\title{
Flora vascular da Serra da Pedra Branca, Caldas, Minas Gerais e relações florísticas com áreas de altitude da Região Sudeste do Brasil ${ }^{1}$
}

\author{
Munike Gonçalves de Rezende ${ }^{2,5}$, Ricardo Cunha Loyola Elias', \\ Fátima Regina Gonçalves Salimena ${ }^{3}$ \& Luiz Menini Neto ${ }^{3,4}$ \\ ${ }^{1}$ Parte das dissertações dos dois primeiros autores no programa de \\ Pós-graduação em Ecologia da Universidade Federal de Juiz de Fora \\ ${ }^{2}$ Programa de Pós-graduação em Ecologia, Universidade Federal de Juiz de Fora - UFJF, \\ CEP 36036-330, Juiz de Fora, MG, Brasil \\ ${ }^{3}$ Departamento de Botânica, Instituto de Ciências Biológicas - ICB, \\ Universidade Federal de Juiz de Fora - UFJF, Campus Universitário s/n., bairro Martelos, \\ CEP 36036-330, Juiz de Fora, MG, Brasil \\ ${ }^{4}$ Centro de Ensino Superior de Juiz de Fora, Campus Arnaldo Janssen, Rua Luz Interior, 100, \\ Santa Luzia, CEP 36030-776, Juiz de Fora, MG, Brasil \\ ${ }^{5}$ Autor para correspondência: Munike Gonçalves de Rezende, e-mail: munikebio@gmail.com
}

REZENDE, M.G., ELIAS, R.C.L., SALIMENA, F.R.G. \& MENINI NETO, L. Vascular flora of Serra da Pedra Branca, Caldas, Minas Gerais and floristic relationships with altitude areas of Southeastern Region of Brazil. Biota Neotrop. 13(4): http://www.biotaneotropica.org.br/v13n4/en/abstract?inventory+bn00513042013

\begin{abstract}
Serra da Pedra Branca (SPB) is a mountain range located in the Southwestern portion of the state Minas Gerais, in the municipality of Caldas $\left(21^{\circ} 58^{\prime}-21^{\circ} 55^{\prime} \mathrm{S}, 46^{\circ} 24^{\prime}-46^{\circ} 22^{\prime} \mathrm{W}\right)$. It is a striking feature in the landscape, between 1100 and 1780 m.s.m., in a region that is part of the Atlantic Forest Domain and is considered as a priority area for conservation of the flora in Minas Gerais state. The vegetation is composed by a mosaic of "campo de altitude" (which occupy the greatest extension in the area), Seasonal Semidecidual Montane Forest, Dense Ombrophilous High-Montane Forest and Mixed Ombrophilous Forest. The aims of this study was the elaboration of a floristic survey of SPB added to the specimens collected by Anders Fredrik Regnell in the nineteenth century in Caldas and to analyze its floristic similarity with altitude areas of the Southeastern Region of Brazil. There were recorded 502 vascular plant species, distributed in 274 genera and 100 families. The majority of recorded species present herbaceous habit, terricolous, saxicolous and/or rupicolous (representing around $58 \%$ of recorded species), predominantly occurring in the "campo de altitude" (ca. 46\%). The richest families were Polypodiaceae (20 spp.) and Dryopteridaceae (10 spp.) among the ferns, and Orchidaceae (56 spp.), Asteraceae (27 spp.) and Fabaceae (26 spp.) among the angiosperms. Just one species of gymnosperm was recorded, Araucaria angustifolia (Bertol.) Kuntze (Araucariaceae). Five new records were made for the Minas Gerais flora, 13 species are cited as threatened with extinction in the state and at least six are endemic to SPB. Amongst 127 species collected in XIX century in the region, only 29 collected again, while 375 new records were made for SPB. The analysis of floristic similarity performed between the flora of SPB and other altitude areas of Southeastern Region revealed isolation of SPB in relation to other areas, highlighting its floristic peculiarity, which can probably be explained by its location in a distinct hydrographic basin. The vegetation of the SPB must be considered as endangered since the presence of endemic species and/or threatened species, associated with local environmental conditions suffering accelerated rate of destruction, highlight the need for urgent actions to preserve local biodiversity.

Keywords: Atlantic Forest, "campo de altitude", "Serra da Mantiqueira", similairy analysis, Southern of Minas Gerais.
\end{abstract}

REZENDE, M.G., ELIAS, R.C.L., SALIMENA, F.R.G. \& MENINI NETO, L. Flora vascular da Serra da Pedra Branca, Caldas, Minas Gerais e relações florísticas com áreas de altitude da Região Sudeste do Brasil. Biota Neotrop. 13(4): http://www.biotaneotropica.org.br/v13n4/pt/abstract?inventory+bn00513042013

Resumo: A Serra da Pedra Branca (SPB) localiza-se no sudoeste do estado de Minas Gerais, no município de Caldas $\left(21^{\circ} 58^{\prime}-21^{\circ} 55^{\prime} \mathrm{S}, 46^{\circ} 24^{\prime}-46^{\circ} 22^{\prime} \mathrm{W}\right)$. É uma feição marcante no relevo, com cotas altimétricas entre 1100 e 1780 m.s.m., inserida no Domínio Atlântico e considerada área prioritária para a conservação da flora no estado de Minas Gerais. Apresenta mosaico composto por campo de altitude (o qual ocupa maior extensão na área), Floresta Estacional Semidecidual Montana, Floresta Ombrófila Densa Alto-Montana e Floresta Ombrófila Mista. Os objetivos do presente estudo foram realizar o levantamento florístico da SPB complementado pelos exemplares coletados na região por Anders Fredrik Regnell e colaboradores no século XIX e analisar a similaridade florística com outras áreas de altitude na Região Sudeste do Brasil. Foram registradas 502 espécies de plantas vasculares, distribuídas em 274 gêneros e 100 famílias. A maioria das espécies registradas apresenta hábito herbáceo terrícola, saxícola e/ou rupícola (representando cerca de 58\% das espécies registradas), ocorrendo predominantemente no campo de altitude (ca. 46\%). As famílias mais ricas foram Polypodiaceae (20 spp.) e Dryopteridaceae (10 spp.) 
dentre as samambaias e Orchidaceae (56 spp.), Asteraceae (27 spp.) e Fabaceae (26 spp.) dentre as angiospermas. Apenas uma espécie de gimnosperma foi registrada, Araucaria angustifolia (Bertol.) Kuntze (Araucariaceae). Cinco novos registros foram feitos para a flora de Minas Gerais, 13 espécies são citadas como ameaçadas de extinção no estado e pelo menos seis são endêmicas da SPB. Dentre as 127 espécies coletadas no século XIX na região, apenas 29 foram recoletadas, enquanto 375 novos registros foram realizados para a SPB. A análise de similaridade realizada entre a flora da SPB e outras áreas de altitude da Região Sudeste revelou um isolamento da área estudada em relação às demais, destacando sua peculiaridade florística, que provavelmente pode ser explicada pela sua localização em uma bacia hidrográfica diferente das demais. A vegetação da SPB deve ser considerada em perigo uma vez que a presença de espécies ameaçadas de extinção e/ou endêmicas, associada às condições ambientais locais com acelerado ritmo de destruição, evidenciam a necessidade de medidas urgentes de preservação da biodiversidade local.

Palavras-chave: Floresta Atlântica, campo de altitude, Serra da Mantiqueira, análise de similaridade, Sul de Minas Gerais.

\section{Introdução}

O Domínio Atlântico representa um complexo de ecossistemas de grande importância, pois abriga uma parcela significativa da diversidade biológica do Brasil e do mundo com uma estimativa de pouco menos de 15800 espécies vegetais, sendo muitas endêmicas (Stehmann et al. 2009), incluído entre os 34 hotspots mundiais de biodiversidade, devido ao elevado número de endemismos e grande perda de habitat (Mittermeier et al. 2005). O processo histórico de colonização do Brasil levou a uma drástica redução de sua cobertura vegetal natural devido às fortes pressões antrópicas como a ocupação desordenada do território, mineração, atividades agropecuárias e industriais que geraram enorme degradação, restando na Floresta Atlântica apenas fragmentos de maior ou menor extensão que representam apenas cerca de 11\% de sua área original (Dean 1996, Brasil 2000, Câmara 2003, Hirota 2003, Ribeiro et al. 2009).

Os campos de altitude representam uma das fitofisionomias do Domínio Atlântico, distribuídos predominantemente no norte da Serra do Mar, no estado do Rio de Janeiro (Serra dos Órgãos) e no Complexo da Mantiqueira entre os quatro estados da Região Sudeste do Brasil (Maciço do Itatiaia, Serra do Brigadeiro, Serra do Caparaó e áreas na região do município de Campos do Jordão), além de localidades isoladas nos estados de São Paulo, Paraná e Santa Catarina (Lutz 1926, Brade 1956, Leoni 1997, Leoni \& Tinte 2004, Caiafa \& Silva 2005, 2007, Garcia \& Pirani 2005, Ribeiro et al. 2007). Difere dos biomas circundantes, frequentemente florestais, pelas características da matriz rochosa, solos e composição da biota, além da fisionomia vegetacional composta predominantemente por mosaico de arbustos e pequenas árvores, inseridos em uma matriz de touceiras de gramíneas herbáceas e bambus, com esparsas ervas e samambaias (Benites et al. 2003, Safford 2007).

A vegetação da Serra da Pedra Branca (SPB), localizada no município de Caldas (região Sul de Minas Gerais) é representada predominantemente por campo de altitude, com fragmentos de Floresta Estacional Semidecidual Montana, Floresta Ombrófila Densa Alto-Montana e Floresta Ombrófila Mista, entremeados às áreas campestres, estando isolada no extremo oeste da Serra da Mantiqueira. Apesar de esta região ter sido visitada no passado por diversos naturalistas como João Barbosa Rodrigues, Gustaf Anders Lindberg, Carl Wilhelm Hjalmar Mosén, Salomon Eberhard Henschen, Johan Friedrik Widgren, dentre outros, poucos estudos sistemáticos sobre a flora da região foram desenvolvidos até o momento. Um dos naturalistas que mais contribuiu para o conhecimento da flora dessa região foi Anders Fredrik Regnell, que chegou ao Brasil em 1841 e permaneceu em Caldas por mais de 40 anos, coletando inúmeras novas espécies de plantas durante este período (Urban 1906, Lindberg 2011).
Segundo Drummond et al. (2005), a região onde se encontra a SPB (Região de Andradas) é considerada área prioritária para a conservação da flora em Minas Gerais e de Importância Biológica Potencial sendo recomendada a investigação científica em forma de inventários uma vez que apresenta reduzido grau de conhecimento científico. Ainda cabe ressaltar o alto grau de ameaça a que estão submetidos os campos de altitude da região, devido à elevada atividade mineradora que ocorre em toda a extensão da SPB, principalmente para extração de granito.

Com isso, alinhado à proposta supracitada de conhecimento da biodiversidade e à escassez de estudos sobre a flora da região (e.g. Machado \& Menini Neto 2010), este estudo teve como objetivos: 1) levantamento da flora vascular da SPB, complementado pelos registros antigos realizados por Regnell e outros pesquisadores no século XIX, além de coletas recentes, depositados em herbários nacionais e estrangeiros, e 2) aplicação destes dados em uma análise de similaridade florística com outras localidades com predominância de vegetação campestre de altitude da região Sudeste do Brasil, com o intuito de avaliar as relações florísticas da SPB com estas áreas.

\section{Material e métodos}

\section{1. Área de estudo}

O maciço da Serra da Pedra Branca (21 ${ }^{\circ} 55^{\prime}-21^{\circ} 58^{\prime}$ 'S e $46^{\circ} 22^{\prime}$ $46^{\circ} 24^{\prime} \mathrm{W}$ ) localiza-se no extremo ocidental da Serra da Mantiqueira, na borda sudeste da caldeira vulcânica de Poços de Caldas (Figuras 1 e 2), unidade geomorfológica denominada Planalto de Poços de Caldas, abrangendo os municípios de Caldas, Santa Rita de Caldas e Ibitiúra de Minas, na Região Sul de Minas Gerais (Leinz \& Amaral 1989, Conforti et al. 2007, Instituto... 2007). Apresenta aproximadamente $17 \mathrm{Km}$ de extensão, disposta em um arco no sentido norte-sul.

A região pertence à Bacia do Rio Paraná, Sub-bacia do Rio Grande. Os principais rios da região são Rio Verde, Ribeirão da Pedra Branca e Ribeirão dos Bugres (Agência... 2005). Esta região representa uma importante área de recarga dos aquíferos profundos, estando entre eles o distrito de Pocinhos do Rio Verde, município de Caldas, conhecido pela presença de diversas fontes de águas sulfurosas e termais (Conforti et al. 2007).

A área estudada apresenta solos típicos de região serrana em relevo montanhoso e escarpado: Solos Litólicos (neossolos) com horizonte A proeminente e textura média e argilosa. Basicamente as seguintes classes de solo podem ser encontradas: Cambissolo com textura argilosa e Podzólico Vermelho-amarelo com argila de atividade baixa e textura média e argilosa, ambos com horizonte A 


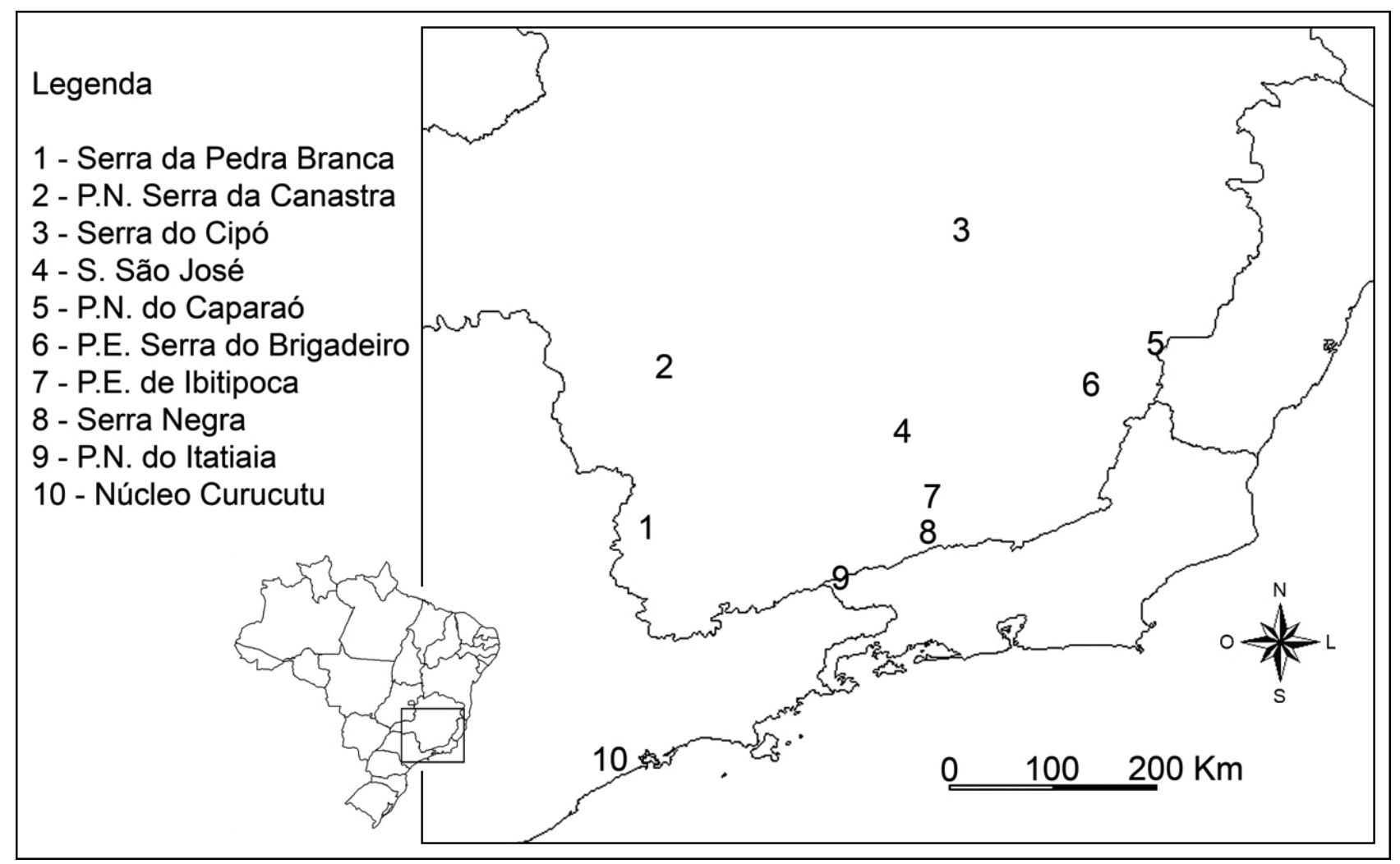

Figura 1. Localização da Serra da Pedra Branca, Caldas, MG e demais áreas utilizadas na análise de similaridade.

Figure 1. Location of Serra da Pedra Branca, Caldas, MG and other areas used in analysis of similarity.

moderado e proeminente. Todos são solos álicos, ou seja, com alto teor de alumínio (Gatto et al. 1983).

A vegetação da região faz parte do Domínio Atlântico e é constituída por um mosaico de fisionomias incluindo Floresta Ombrófila Densa Alto-Montana (FOD), Floresta Estacional Semidecidual Montana (FES), fragmentos de Floresta Ombrófila Mista (FOM), campos de altitude com afloramentos graníticos e áreas antropizadas (Ferri 1980, Veloso et al. 1991, Conforti et al. 2007). O campo de altitude e as áreas antropizadas ocupam aproximadamente $70 \%$ da área, não sendo possível fazer uma delimitação clara entre os dois ambientes, devido à ação antrópica e à prática da pecuária, causando extensos danos às áreas naturais. Os 30\% restantes estão distribuídos pelas fisionomias florestais em vales entremeados às áreas campestres: a FES ocorre em cotas altimétricas mais baixas, entre 1000 e 1500 m.s.m., enquanto a FOD ocorre acima dos 1500 m.s.m., com fragmentos esparsos de FOM em cotas altitudinais similares.

No ano de 2006, através do Decreto Municipal Lei 1.973, foi estabelecida a unidade de conservação de uso sustentável APA Santuário Ecológico da Pedra Branca. AAPA está localizada na região sudoeste do município e apresenta altitudes superiores a 1000 metros, englobando integralmente o distrito de Pocinhos do Rio Verde e parte da área rural do município (Conforti et al. 2007). Nela está inserido parte do complexo serrano que forma a SPB.

O clima da região é tropical, mesotérmico brando úmido, do tipo Cwb pela classificação de Köppen-Geiger (Pell et al. 2007) que se caracteriza por apresentar estações bem definidas (verão chuvoso e inverno seco). O índice pluviométrico anual é de ca. $1500 \mathrm{~mm}$ e a temperatura média anual é $18,2^{\circ} \mathrm{C}$ (Instituto... 2012).

\section{Levantamento florístico}

O levantamento florístico da SPB foi realizado através de expedições mensais, com duração média de três dias cada uma, que percorreram as diversas fitofisionomias da região, no período de março de 2008 a fevereiro de 2009, em três localidades do Distrito de Pocinhos do Rio Verde no município de Caldas, parte integrante da Serra. As localidades apresentam os gradientes altitudinais mais elevados da SPB, entre 1160 e 1780 m.s.m. (Figura 2), sendo a Pedra Branca o ponto de maior altitude da Serra e um dos principais pontos turísticos da região.

Os espécimes foram fotografados e os dados relevantes anotados em campo, posteriormente coletados e herborizados segundo técnicas usuais e incorporados ao Herbário Prof. Leopoldo Krieger (CESJ) da Universidade Federal de Juiz de Fora.

As espécies foram identificadas através de bibliografia especializada, comparações com o acervo do Herbário CESJ, além de consultas a especialistas (destacados após as respectivas famílias na Tabela 1). As famílias de angiospermas estão de acordo com APG III (Angiosperm... 2009) e as de samambaias seguem Smith et al. (2006). A ortografia e conferência das sinonímias foram realizadas com auxílio dos bancos de dados disponíveis na internet: Missouri Botanical Garden (www.tropicos.org), The International Plant Names Index (www.ipni.org), World Checklist of Selected Plant Families (www.kew.org/wcsp). Para os nomes de autores adotou-se Brummitt \& Powell (1992).

Os exemplares provenientes da SPB coletados por Regnell e colaboradores (e.g. Mosén, Barbosa Rodrigues) no século XIX, além das coletas recentes depositados nos herbários BHCB, 


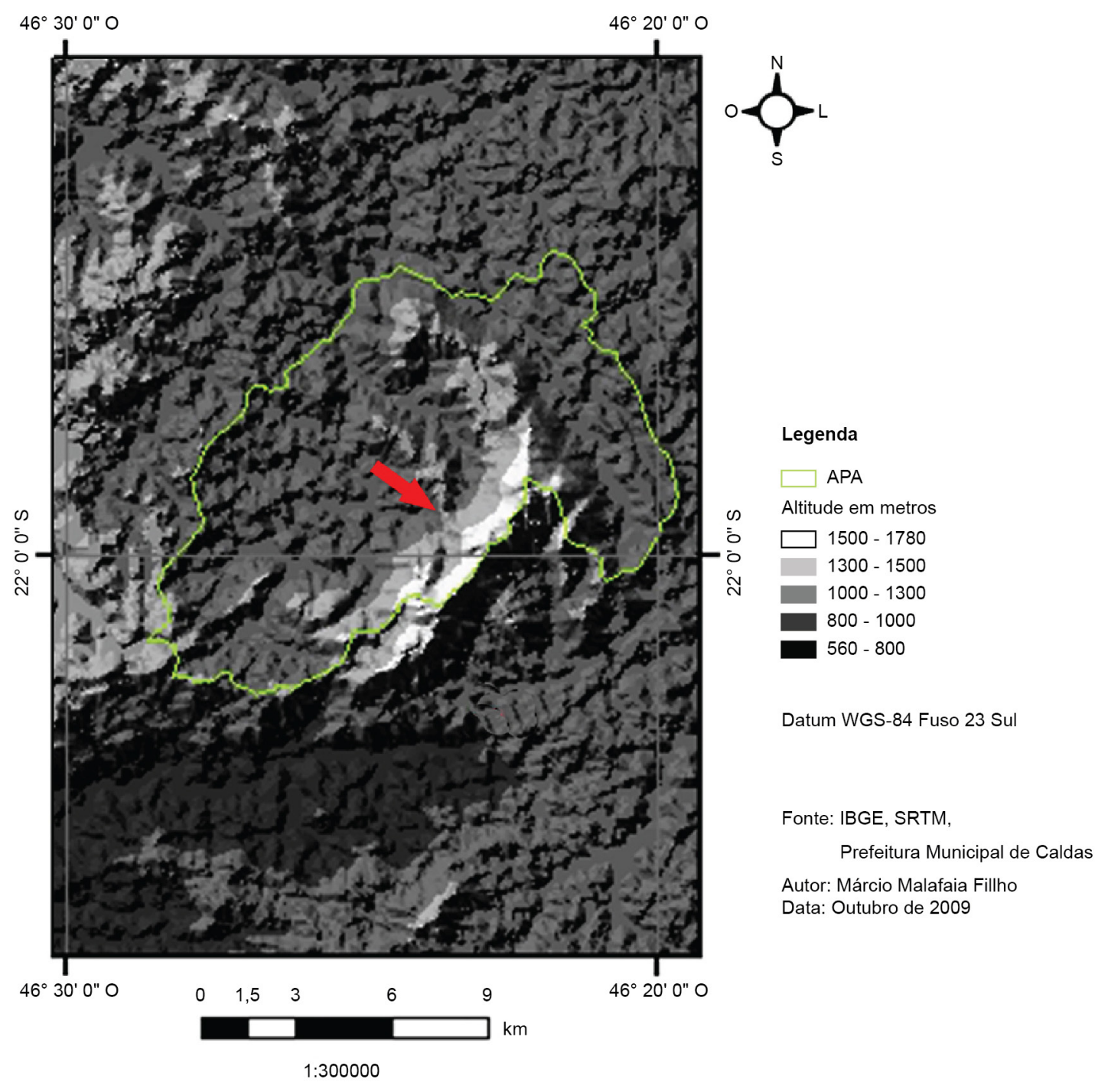

Figura 2. Gradientes altitudinais, destacando a Serra da Pedra Branca (seta), sudeste da APA Santuário Ecológico da Pedra Branca.

Figure 2. Altitudinal gradients, highlighting the Serra da Pedra Branca (arrow), southeast of APA Santuário Ecológico da Pedra Branca.

HUEFS, HSJRP, IAC, MO, NY, S, SP, RB e US, foram utilizados para complementar os dados obtidos no trabalho de campo e estão destacados na Tabela 1. Foram considerados apenas as coletas em que a etiqueta trazia de forma explícita as localidades "Pedra Branca" ou "Serra de Caldas" (antigo topônimo atribuído à Serra da Pedra Branca), em virtude do grande número de coletas realizadas por Regnell em outras localidades do município de Caldas, o qual possuía maior extensão territorial, reduzida em virtude de seu desmembramento em outros municípios, como Andradas e Poços de Caldas.

Os dados das espécies ameaçadas de extinção seguem a "Revisão das Listas das Espécies da Flora Ameaçadas de Extinção para o estado de Minas Gerais" (Biodiversitas 2007) e a "Lista Nacional das Espécies da Flora Brasileira Ameaçadas de Extinção” (Brasil 2008).

\section{Análise de similaridade}

Para a análise de similaridade a flora de angiospermas da Serra da Pedra Branca foi comparada com a de outras nove áreas de altitude com vegetação predominantemente campestre (Figura 1, Tabela 2). Os dados foram obtidos em estudos publicados e na base de dados de acervos de herbários disponível no sítio SpeciesLink, do Centro de Referência em Informação Ambiental (CRIA) (www.splink. org.br). Foram usadas apenas as angiospermas devido à ausência de listagem de samambaias para algumas áreas e, de modo geral onde há, o esforço de coleta foi predominantemente direcionado às angiospermas, estando as samambaias subamostradas. Todas as espécies não identificadas ou com identificação dúbia foram excluídas, de modo que a compilação das listagens resultou em uma planilha de 4607 espécies, usadas na montagem de uma matriz de presença (1) e ausência (0). O método de agrupamento usado foi UPGMA (Unweighted Pair-Group Method with Arithmetic Mean) empregando o índice de similaridade de Jaccard no programa de acesso livre PAST v. 2.15 (Hammer et al. 2001).

\section{Resultados}

Foram registradas 502 espécies de plantas vasculares na SPB, subordinadas a 274 gêneros e 100 famílias.

A distribuição das espécies em cada hábito e habitat está apresentada, respectivamente, nas Figuras 3 e 4 . Há maior predominância de espécies de hábito herbáceo (terrícolas, saxícolas e/ ou rupícolas) que representam cerca de $58 \%$ dos hábitos das espécies. 
Tabela 1. Lista das espécies de plantas vasculares registradas na Serra da Pedra Branca, Minas Gerais.

Table 1. List of vascular plant species recorded in Serra da Pedra Branca, Minas Gerais.

\begin{tabular}{|c|c|c|c|}
\hline Famílias/Espécies & Hábito & Habitat & Material testemunho \\
\hline \multicolumn{4}{|l|}{ SAMAMBAIAS - Alexandre Salino (BHCB), Filipe S. Souza (CESJ) } \\
\hline \multicolumn{4}{|l|}{ ANEMIACEAE -1/2 } \\
\hline Anemia hirsuta (L.) Sw. & et & $\mathrm{ca}$ & Rezende et al. $339 *$ \\
\hline A. villosa Humb. \& Bonpl. ex Willd. & et, er & $\mathrm{ca}$ & Souza et al. $565 *$ \\
\hline \multicolumn{4}{|l|}{ ASPLENIACEAE - 1/8 } \\
\hline Asplenium auriculatum Sw. & ee & $\mathrm{ca}$ & Souza et al. $562 *$ \\
\hline A. auritum Sw. & es & $\mathrm{ca}$ & Rezende et al. $73 *$ \\
\hline A. formosum Willd. & et & $\mathrm{ca}$ & Rezende et al. $340 *$ \\
\hline A. incurvatum Fée & et, er & $\mathrm{ca}, \mathrm{ma}$ & Souza et al. $546^{*}$ \\
\hline A. feei Kunze ex Fée & er & $\mathrm{ma}$ & Souza et al. $569 *$ \\
\hline A. cf. kunzeanum Klotzsch ex Rosenst. & et & $\mathrm{ma}$ & Souza et al. $568 *$ \\
\hline A. praemorsum $\mathrm{Sw}$. & ee & $\mathrm{ma}$ & Rezende et al. $315 *$ \\
\hline A. serra Langsd. \& Fisch. & et & ma & Souza et al. $557 *$ \\
\hline \multicolumn{4}{|l|}{ BLECHNACEAE - 1/1 } \\
\hline Blechnum binervatum (Desv.) R.M. Tryon \& Stolze & et & $\mathrm{ma}$ & Monteiro et al. $492 *$ \\
\hline \multicolumn{4}{|l|}{ CYATHEACEAE - 1/1 } \\
\hline Cyathea phalerata Mart. & arb & $\mathrm{ma}$ & Valente et al. $503 *$ \\
\hline \multicolumn{4}{|l|}{ DICKSONIACEAE - 1/1 } \\
\hline Dicksonia sellowiana Hook. & arb & $\mathrm{ma}$ & Valente et al. $501 *$ \\
\hline \multicolumn{4}{|l|}{ DRYOPTERIDACEAE - 4/10 } \\
\hline Elaphoglossum burchellii (Baker) C. Chr. & et, er, es & ca, bm, aa & Rezende et al. $35 * * *$ \\
\hline E. gayanum (Fée) T. Moore & es & $\mathrm{ca}$ & Rezende et al. $167 *$ \\
\hline E. iguapense Brade & ee & $\mathrm{ma}$ & Krapovickas $35463(\mathrm{MO}) *$ \\
\hline E. lindbergii (Mett. ex Kuhn) Rosenst. & es & $\mathrm{ma}$ & Mosén $2250(\mathrm{~S}) * *$ \\
\hline E. piloselloides (C. Presl) T. Moore & - & - & Regnell III 1434 (S) ** \\
\hline E. tectum (Humb. \& Bonpl. ex Willd.) T. Moore & er & $\mathrm{ca}$ & Mosén $2254(\mathrm{~S}) * *$ \\
\hline E. vagans (Mett.) Hieron. & es & $\mathrm{ca}$ & Souza et al. $535 * * *$ \\
\hline Megalastrum connexum (Kaulf.) A.R. Sm. \& R.C. Moran & et, es & $\mathrm{ma}$ & Mosén $2187(\mathrm{~S}) * *$ \\
\hline Polystichum montevidense (Spreng.) Rosenst. & et & $\mathrm{ma}$ & Souza et al. $559 *$ \\
\hline Rumohra adiantiformis (G. Forst.) Ching & et & $\mathrm{ca}$ & Souza et al. $556^{*}$ \\
\hline \multicolumn{4}{|l|}{ HYMENOPHYLLACEAE - 1/1 } \\
\hline Hymenophyllum polyanthos (Sw.) Sw. & ee & $\mathrm{ma}$ & Souza et al. $564 *$ \\
\hline \multicolumn{4}{|l|}{ LYCOPODIACEAE - 1/1 } \\
\hline Huperzia regnellii (Maxon) B.Øllg. \& P.G.Windisch & er, es & $\mathrm{ca}$ & Rezende et al. $157 *$ \\
\hline \multicolumn{4}{|l|}{ OPHIOGLOSSACEAE - 1/1 } \\
\hline Botrychium virginianum (L.) Sw. & et & ma & Rezende et al. $269 *$ \\
\hline \multicolumn{4}{|l|}{ POLYPODIACEAE - 9/20 } \\
\hline Campyloneurum acrocarpon Fée & ee & $\mathrm{bm}$ & Rezende et al. $49 *$ \\
\hline C. austrobrasilianum (Alston) de la Sota & ee & $\mathrm{bm}, \mathrm{ma}$ & Rezende et al. $50 *$ \\
\hline C. nitidum (Kaulf.) C. Presl & ee & $\mathrm{ma}$ & Souza et al. $567 *$ \\
\hline C. vulpinum (Lindm.) Ching + & ee & ma & Mosén $2220(\mathrm{~S}) * *$ \\
\hline Lellingeria apiculata (Kunze ex Klotzsch) A.R.Sm. \& R.C. Moran & ee & $\mathrm{ma}$ & Mosén $2194(\mathrm{~S}) * *$ \\
\hline $\begin{array}{l}\text { Melpomene pilosissima (M.Martens \& Galeotti) A.R.Sm. \& R.C. } \\
\text { Moran }\end{array}$ & er, es & $\mathrm{ca}, \mathrm{ma}$ & Rezende et al. $70 *$ \\
\hline Microgramma squamulosa (Kaulf.) de la Sota & ee & $\mathrm{ca}$ & Souza et al. $550 *$ \\
\hline
\end{tabular}

Espécies destacadas em negrito são aquelas citadas na lista de espécies ameaçadas da flora de Minas Gerais (Biodiversitas 2007): 0 "Criticamente em

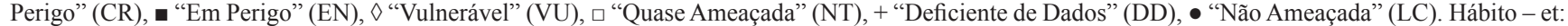
erva terrícola, ee: erva epífita, es: erva saxícola, er: erva rupícola, av: árvore, ab: arbusto, li - liana. Habitat - ca: campo de altitude, ma: interior de mata, bm: borda de mata, aa: área antrópica. Material testemunho: está citado um exemplar para cada espécie. * espécies coletadas apenas no presente estudo ou coletadas recentemente e depositadas nos acervos dos herbários analisados; ** espécies coletadas apenas por Regnell ou colaboradores no século XIX; *** espécies coletadas em ambos os casos.

Species in bold are those cited in the list of threatened species of Minas Gerais flora (Biodiversitas 2007): O "Critically endangered" (CR), " "Endangered" (EN), $\diamond$ "Vulnerable" (VU), $\square$ "Near Threatened" (NT), + "Data Defficient" (DD), • "Least Concern" (LC). Hábito - et: terrestrial herb, ee: epiphyte herb, es: saxicolous herb, er: rupicolous herb, av: tree, ab: shrub, li - liana. Habitat - ca: campo de altitude, ma: forest interior, bm: forest edge, aa: anthropic area. Material testemunho: one specimen is cited for each species. * species collected only on the present study or recently collected and deposited in the analyzed herbaria; ** species collected only by Regnell or collaborators in XIX century; *** species collected on both cases. 
Tabela 1. Continuação...

Table 1. Continued...

\begin{tabular}{|c|c|c|c|}
\hline Famílias/Espécies & Hábito & Habitat & Material testemunho \\
\hline Niphidium crassifolium (L.) Lellinger & ee, er & ma & Valente et al. $490 *$ \\
\hline Pecluma camptophyllaria (Fée) M.G. Price & er & $\mathrm{ca}$ & Souza et al. $543 * * *$ \\
\hline P. filicula (Kaulf.) M.G. Price & er & ca & Regnell III 1441 (S) ** \\
\hline P. pectinatiformis (Lindm.) M.G. Price & es & $\mathrm{ma}$ & Mosén $2198(\mathrm{~S}) * *$ \\
\hline P. singeri (de la Sota) M.G. Price & ee & ma & Rezende et al. $71 * * *$ \\
\hline P. truncorum (Lindm.) M.G.Price & ee & ma & Regnell $1473(\mathrm{MO}) * *$ \\
\hline Phlebodium pseudoaureum (Cav.) Lellinger & es & $\mathrm{ca}$ & Rezende \& Elias $269 *$ \\
\hline Pleopeltis angusta Humb \& Bonpl. ex Willd & ee & $\mathrm{bm}$ & Rezende et al. $48 *$ \\
\hline P. hirsutissima (Raddi) de la Sota & er & $\mathrm{ca}$ & Souza et al. $538 *$ \\
\hline P. macrocarpa (Bory ex Willd.) Kaulf. & ee & $\mathrm{ca}$ & Rezende \& Elias $264 *$ \\
\hline P. cf. pleopeltidis (Fée) de la Sota & et, er & $\mathrm{ca}, \mathrm{bm}$ & Rezende \& Elias $266 *$ \\
\hline Serpocaulon catharinae (Langsd. \& Fisch.) A.R. Sm. & et & $\mathrm{ca}$ & Rezende \& Elias $260 *$ \\
\hline S. cf. latipes (Langsd. \& Fisch.) A.R. Sm. & et & ma & Souza et al. $566 *$ \\
\hline \multicolumn{4}{|l|}{ PTERIDACEAE - 4/9 } \\
\hline Adiantopsis radiata (L.) Fée & et & aa & Souza et al. $659 *$ \\
\hline Cheilanthes regnelliana Mett. $\diamond$ & er, es & $\mathrm{ca}$ & Rezende et al. $72 * * *$ \\
\hline Cheilanthes sp. & et & $\mathrm{ca}$ & Rezende et al. $341 *$ \\
\hline Doryopteris collina (Raddi) J. Sm. & er, es & $\mathrm{ca}$ & Elias et al. $29 *$ \\
\hline D. crenulans (Fée) H. Christ & et & aa & Machado et al. $125 *$ \\
\hline D. majestosa Yesilyurt & et & $\mathrm{ca}$ & Souza et al. $561 *$ \\
\hline D. nobilis (T. Moore) C. Chr. & et & bm, ma & Souza et al. $551 *$ \\
\hline D. ornithopus (Mett.) J. Sm. & er & $\mathrm{ca}$ & Souza et al. $554 *$ \\
\hline Pteris deflexa Link & et & $\mathrm{ca}$ & Souza et al. $573 *$ \\
\hline \multicolumn{4}{|l|}{ THELYPTERIDACEAE - 1/1 } \\
\hline Thelypteris regnelliana (C. Chr.) Ponce & et & $\mathrm{ma}$ & Souza et al. $572 *$ \\
\hline \multicolumn{4}{|l|}{ WOODSIACEAE - 1/3 } \\
\hline Diplazium ambiguum Raddi & es & $\mathrm{ma}$ & Regnell $1473(\mathrm{MO}) * *$ \\
\hline D. cristatum (Desr.) Alston & es & $\mathrm{ma}$ & Regnell 1473d (S) ** \\
\hline D. lindbergii (Mett.) Christ. & et & $\mathrm{ma}$ & Souza et al. $563 *$ \\
\hline \multicolumn{4}{|l|}{ GIMNOSPERMAS } \\
\hline \multicolumn{4}{|l|}{ ARAUCARIACEAE - 1/1 } \\
\hline Araucaria angustifolia (Bertol.) Kuntze & av & aa & Souza et al. $665 *$ \\
\hline \multicolumn{4}{|l|}{ ANGIOSPERMAS } \\
\hline \multicolumn{4}{|l|}{ ACANTHACEAE - 1/2 } \\
\hline Ruellia jussieuoides Schltdl. \& Cham. & et & ca & Regnell I 373 (S) ** \\
\hline Ruellia sp. & er & bm, ma & Rezende et al. $133 *$ \\
\hline \multicolumn{4}{|l|}{ ALSTROEMERIACEAE $-2 / 4$} \\
\hline Alstroemeria cunha Vell. • & et & $\mathrm{bm}$ & Regnell III 1230 (S) ** \\
\hline A. foliosa Mart. $\diamond$ & et & $\mathrm{ca}$ & Hoehne $2882(\mathrm{NY}) *$ \\
\hline A. variegata M.C.Assis $\bigcirc$ & er & $\mathrm{ca}, \mathrm{ma}$ & Elias et al. $36^{*}$ \\
\hline Bomarea edulis (Tussac) Herb. & li & $\mathrm{ma}$ & Rezende et al. $291 \mathrm{~b} *$ \\
\hline \multicolumn{4}{|l|}{ AMARANTHACEAE - 3/5 } \\
\hline Alternanthera brasiliana (L.) Kuntze & et & $\mathrm{ca}$ & Krapovickas 35488 (MO) * \\
\hline Alternanthera sp. & et & $\mathrm{ca}$ & Rezende et al. $314^{*}$ \\
\hline
\end{tabular}

Espécies destacadas em negrito são aquelas citadas na lista de espécies ameaçadas da flora de Minas Gerais (Biodiversitas 2007): 0 "Criticamente em

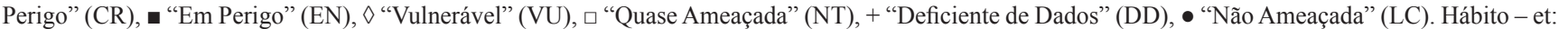
erva terrícola, ee: erva epífita, es: erva saxícola, er: erva rupícola, av: árvore, ab: arbusto, li - liana. Habitat - ca: campo de altitude, ma: interior de mata, bm: borda de mata, aa: área antrópica. Material testemunho: está citado um exemplar para cada espécie. * espécies coletadas apenas no presente estudo ou coletadas recentemente e depositadas nos acervos dos herbários analisados; ** espécies coletadas apenas por Regnell ou colaboradores no século XIX; *** espécies coletadas em ambos os casos.

Species in bold are those cited in the list of threatened species of Minas Gerais flora (Biodiversitas 2007): O "Critically endangered" (CR), $\mathbf{\text { a }}$ "Endangered"

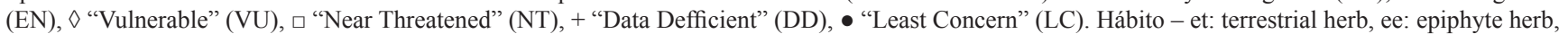
es: saxicolous herb, er: rupicolous herb, av: tree, ab: shrub, li - liana. Habitat - ca: campo de altitude, ma: forest interior, bm: forest edge, aa: anthropic area. Material testemunho: one specimen is cited for each species. * species collected only on the present study or recently collected and deposited in the analyzed herbaria; ${ }^{* *}$ species collected only by Regnell or collaborators in XIX century; ${ }^{* * *}$ species collected on both cases. 
Tabela 1. Continuação...

Table 1. Continued..

\begin{tabular}{|c|c|c|c|}
\hline Famílias/Espécies & Hábito & Habitat & Material testemunho \\
\hline Chamissoa altissima (Jacq.) Kunth & et & $\mathrm{ma}$ & Monteiro et al. $470 *$ \\
\hline Iresine diffusa Humb. \& Bonpl. ex Willd. & et, es & ca, aa & Monteiro et al. $471 *$ \\
\hline INDET. & ee & $\mathrm{bm}$ & Rezende et al. $302 *$ \\
\hline \multicolumn{4}{|l|}{ AMARYLLIDACEAE - 1/1 } \\
\hline Hippeastrum psittacinum (Ker Gawl.) Herb. & er & ca & Elias et al. $43 *$ \\
\hline \multicolumn{4}{|l|}{ ANACARDIACEAE - 1/1 } \\
\hline Lithraea molleoides Engl. & av & $\mathrm{ca}, \mathrm{ab}, \mathrm{aa}$ & Rezende \& Elias $28 *$ \\
\hline \multicolumn{4}{|l|}{ ANNONACEAE - 1/1 } \\
\hline Annona sylvatica A. St.-Hil. & av & aa & Machado et al. $147 *$ \\
\hline \multicolumn{4}{|l|}{ APIACEAE - 2/4 } \\
\hline Apium leptophyllum (Pers.) F. Muell. ex Benth. & et & ca, aa & Machado et al. $129 *$ \\
\hline Eryngium ebracteatum Lam. & et & $\mathrm{ca}$ & Rezende et al. $189 *$ \\
\hline E. eurycephalum Malme & et & $\mathrm{ca}$ & Rezende et al. $27 *$ \\
\hline E. regnellii Malme & et & $\mathrm{ca}$ & Mosén $541(\mathrm{~S}) * *$ \\
\hline \multicolumn{4}{|c|}{ APOCYNACEAE - Carolina N. Matozinhos (CESJ) - 9/15 } \\
\hline Asclepias bracteolata E. Fourn. & et & $\mathrm{ca}$ & Regnell $187(\mathrm{RB}) * *$ \\
\hline A. candida Vell. & et & $\mathrm{ca}$ & van den Berg 1283 (HUEFS) * \\
\hline A. curassavica $\mathrm{L}$. & et & bm, aa & Rezende \& Elias $241 *$ \\
\hline Aspidosperma parvifolium A. DC. & av & aa & Souza et al. $662 *$ \\
\hline Gonolobus rostratus (Vell.) R.Br. & li & $\mathrm{bm}$ & Regnell $1601(\mathrm{MO}) * *$ \\
\hline Jobinia lindbergii E.Fourn. & li & $\mathrm{bm}$ & Mosén $951(\mathrm{MO}) * *$ \\
\hline Mandevilla emarginata (Vell.) C. Ezcurra & li & aa & Souza et al. $651 *$ \\
\hline M. hirsuta (Rich.) K. Schum. & li & $\mathrm{ca}$ & Machado et al. $119 *$ \\
\hline M. venulosa (Müll. Arg.) Woodson & li & $\mathrm{ca}$ & Rezende et al. $81 *$ \\
\hline Marsdenia montana Malme & li & $\mathrm{bm}$ & Regnell $893(\mathrm{MO}) * *$ \\
\hline Orthosia scoparia (Nutt.) Liede \& Meve & li & $\mathrm{ca}, \mathrm{bm}$ & Rezende et al. $128 *$ \\
\hline Oxypetalum multiflorum (Malme) Malme & li & $\mathrm{ma}$ & Regnell III 892 (S) ** \\
\hline O. regnellii (Malme) Malme & li & $\mathrm{bm}$ & Regnell III $73(\mathrm{~S}) * *$ \\
\hline Pseudibatia suberosa Malme & li & bm & Mosén $4283(\mathrm{~S}) * *$ \\
\hline INDET. & li & bm & Machado et al. $164 *$ \\
\hline \multicolumn{4}{|l|}{ APODANTHACEAE - 1/1 } \\
\hline Pilostyles ingae (H. Karst.) Hook. f. & ee & bm, aa & Souza et al. $672 *$ \\
\hline \multicolumn{4}{|l|}{ ARACEAE - Marcus Nadruz Coelho (RB) - 1/1 } \\
\hline Anthurium minarum Sakuragui \& Mayo & es & ca & Rezende et al. $74 *$ \\
\hline \multicolumn{4}{|l|}{ ARALIACEAE - 2/2 } \\
\hline Dendropanax cuneatus (DC.) Decne. \& Planch. & av & $\mathrm{bm}$ & Rezende et al. $55 *$ \\
\hline Hydrocotyle barbarossae Cham. \& Schltdl. & et & ma, aa & Rezende et al. $123 *$ \\
\hline \multicolumn{4}{|l|}{ ARISTOLOCHIACEAE - 1/1 } \\
\hline Aristolochia burchellii Mast. & li & aa & Rezende \& Elias $214 *$ \\
\hline \multicolumn{4}{|c|}{ ASTERACEAE - Aristônio M. Teles (UFGO), Jimi N. Nakajima (HUFU), Mariana M. Saavedra (RB) - 18/27 } \\
\hline Ayapana amygdalina (Lam.) R.M.King \& H.Rob & $a b$ & $\mathrm{ca}$ & Rezende \& Elias $10 *$ \\
\hline Baccharidastrum triplinervium (Less.) Cabr. & $a b$ & $\mathrm{ca}$ & Rezende et al. $278 *$ \\
\hline Baccharis caprariifolia DC. & $a b$ & $\mathrm{ca}$ & Regnell III $750(\mathrm{~S}) * *$ \\
\hline Bidens graveolens Mart. & et & $\mathrm{ca}$ & Regnell II 164 (S) ** \\
\hline
\end{tabular}

Espécies destacadas em negrito são aquelas citadas na lista de espécies ameaçadas da flora de Minas Gerais (Biodiversitas 2007): $\mathrm{O}$ "Criticamente em

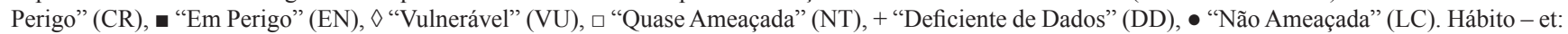
erva terrícola, ee: erva epífita, es: erva saxícola, er: erva rupícola, av: árvore, ab: arbusto, li - liana. Habitat - ca: campo de altitude, ma: interior de mata, bm: borda de mata, aa: área antrópica. Material testemunho: está citado um exemplar para cada espécie. * espécies coletadas apenas no presente estudo ou coletadas recentemente e depositadas nos acervos dos herbários analisados; ** espécies coletadas apenas por Regnell ou colaboradores no século XIX; *** espécies coletadas em ambos os casos.

Species in bold are those cited in the list of threatened species of Minas Gerais flora (Biodiversitas 2007): O "Critically endangered" (CR), "Endangered" $(\mathrm{EN}), \diamond$ "Vulnerable" (VU), $\square$ "Near Threatened" (NT), + "Data Defficient" (DD), • "Least Concern" (LC). Hábito - et: terrestrial herb, ee: epiphyte herb, es: saxicolous herb, er: rupicolous herb, av: tree, ab: shrub, li - liana. Habitat - ca: campo de altitude, ma: forest interior, bm: forest edge, aa: anthropic area. Material testemunho: one specimen is cited for each species. * species collected only on the present study or recently collected and deposited in the analyzed herbaria; ** species collected only by Regnell or collaborators in XIX century; *** species collected on both cases. 
Tabela 1. Continuação...

Table 1. Continued..

\begin{tabular}{|c|c|c|c|}
\hline Famílias/Espécies & Hábito & Habitat & Material testemunho \\
\hline Calea mediterranea (Vell.) Pruski & et & $\mathrm{ca}$ & Regnell III $787(\mathrm{~S}) * *$ \\
\hline Calea sp. & $a b$ & $\mathrm{ca}$ & Rezende \& Elias $6 *$ \\
\hline $\begin{array}{l}\text { Campuloclinium purpurascens (Sch. Bip. ex Baker) R.M. King \& } \\
\text { H. Rob. }\end{array}$ & es & $\mathrm{ca}$ & Monteiro et al. $481 *$ \\
\hline Chrysolaena herbacea (Vell.) H. Rob. & er & ca & Rezende \& Elias $14 *$ \\
\hline Cirsium vulgare (Savi) Ten. & $a b$ & aa & Souza et al. $667 *$ \\
\hline Dasyphyllum flagellare (Casar.) Cabrera $\diamond$ & $a b$ & $\mathrm{ca}$ & Ramos \& Conforti 235 (IAC) $* * *$ \\
\hline D. synacanthum (Baker) Cabr. + & li & $\mathrm{ca}$ & Lindberg $19(\mathrm{~S}) * *$ \\
\hline D. tomentosum (Spreng.) Cabrera & av & $\mathrm{bm}$ & Valente et al. $505 * * *$ \\
\hline Eupatoriopsis hoffmanniana Hieron. & es, et & $\mathrm{ca}$ & Regnell III 684 (S) ** \\
\hline Hieracium warmingii Baker & et & $\mathrm{ca}$ & Regnell III 817 (S) ** \\
\hline Hypochaeris gardneri Baker & et & $\mathrm{ca}$ & Rezende \& Elias $251 *$ \\
\hline Leptostelma maximum (D. Don) Otto ex DC. & $a b$ & $\mathrm{ca}$ & Rezende \& Elias $11 *$ \\
\hline Mikania decumbens Malme • & li & $\mathrm{bm}$ & Regnell III 1739 (S) ** \\
\hline M. pseudohoffmanniana G.M. Barroso ex W.C. Holmes & li & $\mathrm{bm}$ & Mosén $3973(\mathrm{~S}) * *$ \\
\hline Senecio brasiliensis (Spreng.) Less. & et & $\mathrm{ca}$ & Rezende et al. $178 *$ \\
\hline Stevia decussata Baker $\diamond$ & $a b$ & $\mathrm{ca}$ & Regnell III 677 (S) ** \\
\hline S. menthifolia Sch.Bip. ex Baker & $a b$ & $\mathrm{ca}$ & Rezende et al. $77 *$ \\
\hline Trixis verbasciformis Less. & et & $\mathrm{ca}$ & Rezende et al. $138 *$ \\
\hline Trixis sp. & et & $\mathrm{bm}$ & Rezende et al. $264 *$ \\
\hline Verbesina cf. glabrata Hook. \& Arn. & et & $\mathrm{ca}$ & Rezende et al. $41 *$ \\
\hline Vernonia membranacea Gardner & et & $\mathrm{ca}$ & Rezende et al. $187 *$ \\
\hline INDET.1 & et & $\mathrm{ca}$ & Rezende \& Elias $218 *$ \\
\hline INDET.2 & et & $\mathrm{ca}$ & Rezende et al. $78 *$ \\
\hline \multicolumn{4}{|l|}{ BEGONIACEAE - 1/2 } \\
\hline Begonia angulata Vell & et & ma & Rezende et al. $195 *$ \\
\hline B. geniculata Vell. & er & $\mathrm{ca}$ & Souza et al. $669 *$ \\
\hline \multicolumn{4}{|l|}{ BIGNONIACEAE - 4/6 } \\
\hline Dolichandra unguis-cati (L.) L.G.Lohmann & li & bm & Mosén $4332(\mathrm{MO}) * *$ \\
\hline Fridericia leucopogon (Cham.) L.G. Lohmann & et & $\mathrm{ca}$ & Rezende et al. $334 *$ \\
\hline Pyrostegia venusta (Ker Gawl.) Miers & li & $\mathrm{ca}$ & Rezende et al. $362 *$ \\
\hline Tabebuia alba (Cham.) Sandwith $\diamond$ & av & $\mathrm{ca}$ & Torres et al. 1927 (IAC) * \\
\hline Tabebuia sp. 1 & av & $\mathrm{ca}$ & Rezende et al. $182 *$ \\
\hline Tabebuia sp.2 & av & $\mathrm{ca}$ & Elias et al. $38 *$ \\
\hline \multicolumn{4}{|l|}{ BORAGINACEAE - 1/3 } \\
\hline Cordia ecalyculata Vell. & av & $\mathrm{bm}$ & Rezende et al. $61 *$ \\
\hline Cordia sp.1 & $a b$ & $\mathrm{ca}$ & Rezende \& Elias $229 *$ \\
\hline Cordia sp.2 & av & $\mathrm{ca}$ & Monteiro et al. $489 *$ \\
\hline \multicolumn{4}{|l|}{ BROMELIACEAE - Talita M. Machado (BHCB) - 7/15 } \\
\hline Aechmea distichantha Lem. & ee, et, er & $\mathrm{ca}, \mathrm{ma}$ & Machado et al. $75 *$ \\
\hline A. nudicaulis (L.) Griseb. & ee, et, er & $\mathrm{ca}$ & Rezende et al. $33 * * *$ \\
\hline Billbergia distachia (Vell.) Mez & ee, er, es & ma & Rezende et al. $153 *$ \\
\hline Bromelia regnellii $\mathrm{Mez}$ & et & bm, ma & Machado et al. $93 *$ \\
\hline Pitcairnia caldasiana Baker & er & $\mathrm{ca}$ & Regnell III 1253 (S) ** \\
\hline
\end{tabular}

Espécies destacadas em negrito são aquelas citadas na lista de espécies ameaçadas da flora de Minas Gerais (Biodiversitas 2007): O "Criticamente em

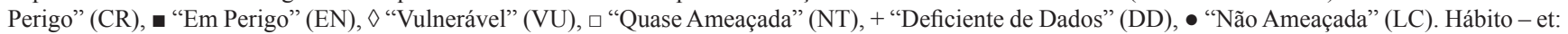
erva terrícola, ee: erva epífita, es: erva saxícola, er: erva rupícola, av: árvore, ab: arbusto, li - liana. Habitat - ca: campo de altitude, ma: interior de mata, bm: borda de mata, aa: área antrópica. Material testemunho: está citado um exemplar para cada espécie. * espécies coletadas apenas no presente estudo ou coletadas recentemente e depositadas nos acervos dos herbários analisados; ** espécies coletadas apenas por Regnell ou colaboradores no século XIX; *** espécies coletadas em ambos os casos.

Species in bold are those cited in the list of threatened species of Minas Gerais flora (Biodiversitas 2007): $\bigcirc$ "Critically endangered" (CR), — "Endangered"

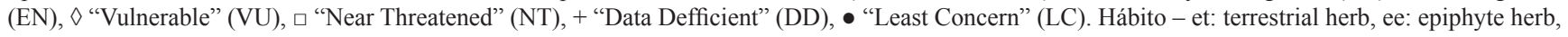
es: saxicolous herb, er: rupicolous herb, av: tree, ab: shrub, li - liana. Habitat - ca: campo de altitude, ma: forest interior, bm: forest edge, aa: anthropic area. Material testemunho: one specimen is cited for each species. * species collected only on the present study or recently collected and deposited in the analyzed herbaria; ** species collected only by Regnell or collaborators in XIX century; *** species collected on both cases. 
Tabela 1. Continuação...

Table 1. Continued...

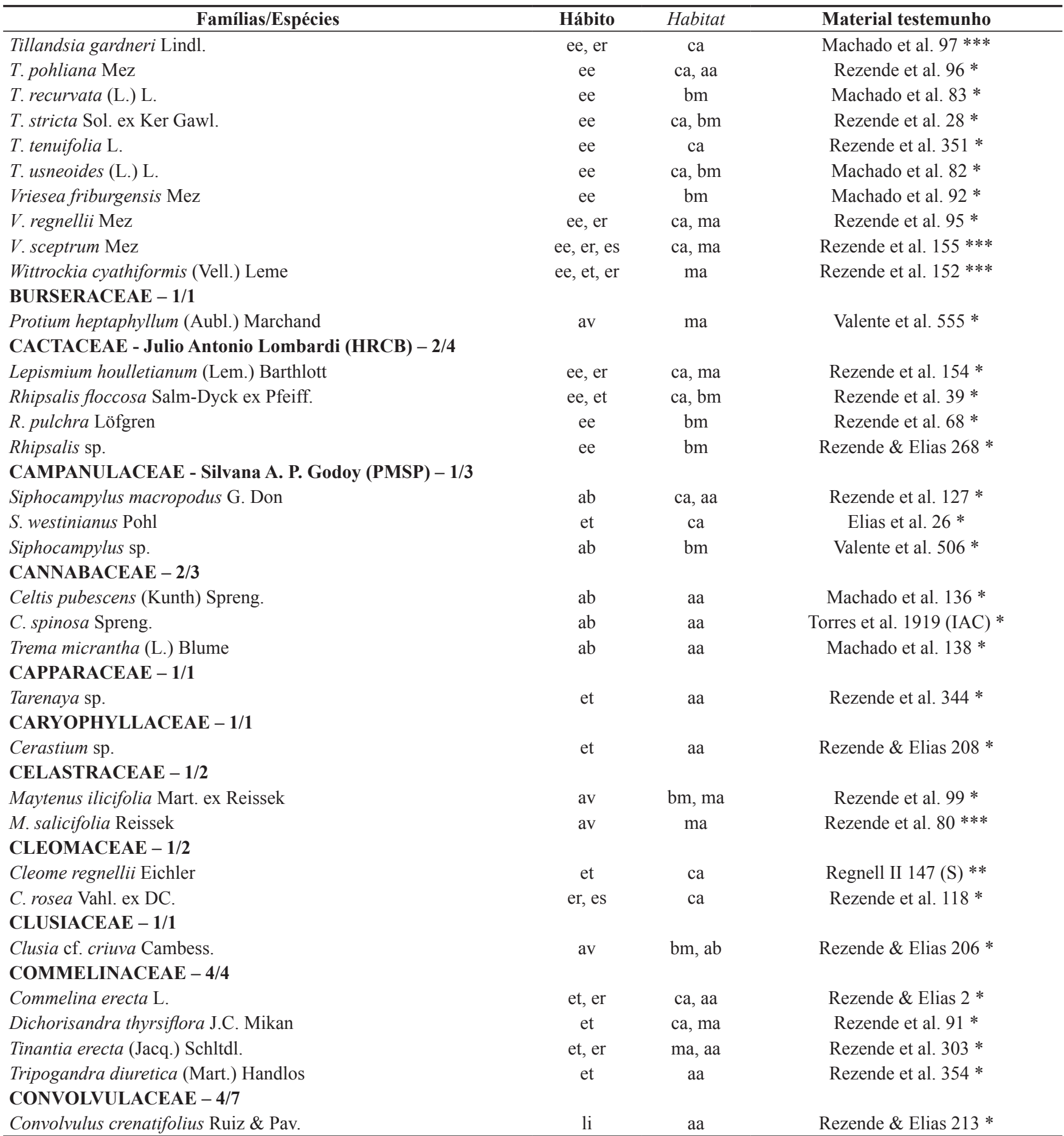

Espécies destacadas em negrito são aquelas citadas na lista de espécies ameaçadas da flora de Minas Gerais (Biodiversitas 2007): $\mathrm{O}$ "Criticamente em

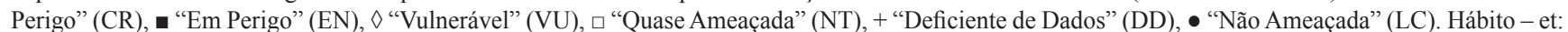
erva terrícola, ee: erva epífita, es: erva saxícola, er: erva rupícola, av: árvore, ab: arbusto, li - liana. Habitat - ca: campo de altitude, ma: interior de mata, bm: borda de mata, aa: área antrópica. Material testemunho: está citado um exemplar para cada espécie. * espécies coletadas apenas no presente estudo ou coletadas recentemente e depositadas nos acervos dos herbários analisados; ** espécies coletadas apenas por Regnell ou colaboradores no século XIX; *** espécies coletadas em ambos os casos.

Species in bold are those cited in the list of threatened species of Minas Gerais flora (Biodiversitas 2007): O "Critically endangered" (CR), घ "Endangered" $(\mathrm{EN}), \diamond$ "Vulnerable" (VU), $\square$ "Near Threatened" (NT), + "Data Defficient" (DD), • "Least Concern" (LC). Hábito - et: terrestrial herb, ee: epiphyte herb, es: saxicolous herb, er: rupicolous herb, av: tree, ab: shrub, li - liana. Habitat - ca: campo de altitude, ma: forest interior, bm: forest edge, aa: anthropic area. Material testemunho: one specimen is cited for each species. * species collected only on the present study or recently collected and deposited in the analyzed herbaria; ${ }^{* *}$ species collected only by Regnell or collaborators in XIX century; *** species collected on both cases. 
Tabela 1. Continuação...

Table 1. Continued..

\begin{tabular}{|c|c|c|c|}
\hline Famílias/Espécies & Hábito & Habitat & Material testemunho \\
\hline Evolvulus lithospermoides Mart. & et & aa & Souza et al. $653^{*}$ \\
\hline Ipomoea purpurea (L.) Roth & li & aa & Rezende et al. $356^{*}$ \\
\hline I. regnellii Meisn. & li & bm, aa & Rezende \& Elias $265 *$ \\
\hline Ipomoea sp.1 & $a b$ & $\mathrm{ca}$ & Gimenes et al. $3 *$ \\
\hline Ipomoea sp.2 & li & bm & Rezende et al. $288 *$ \\
\hline Jacquemontia evolvuloides Meissn. & li & $\mathrm{ca}$ & Ramos \& Conforti 219 (IAC) *** \\
\hline \multicolumn{4}{|l|}{ CUCURBITACEAE - 3/3 } \\
\hline Fevillea trilobata $\mathrm{L}$. & li & $\mathrm{ca}$ & Souza et al. $670 *$ \\
\hline Cayaponia diversifolia (Cogn.) Cogn. & li & $\mathrm{ca}$ & Regnell III $630(\mathrm{~S}) * *$ \\
\hline Cyclanthera hystrix (Gillies) Arn. & li & $\mathrm{ca}$ & Regnell III 633 x a (S) ** \\
\hline \multicolumn{4}{|l|}{ CUNONIACEAE - 1/1 } \\
\hline Lamanonia ternata Vell. & av & $\mathrm{ca}, \mathrm{bm}, \mathrm{aa}$ & Rezende \& Elias $210 *$ \\
\hline \multicolumn{4}{|l|}{ CYPERACEAE - 4/10 } \\
\hline Bulbostylis cf. juncoides (Vahl) Kük. ex Osten & et & $\mathrm{ca}$ & Rezende \& Elias $261 *$ \\
\hline B. scabra (J. Presl \& C. Presl) C.B. Clarke • & et & $\mathrm{ca}$ & Mosén $4456(\mathrm{~S}) * *$ \\
\hline Bulbostylis sp. & et & $\mathrm{ca}$ & Rezende et al. $30 *$ \\
\hline Carex hilairei Boott & et & $\mathrm{ca}$ & Regnell III 1326 (S) ** \\
\hline Cyperus sp.1 & et & aa & Rezende et al. $347 *$ \\
\hline Cyperus sp. 2 & et & $\mathrm{ca}$ & Machado et al. $142 *$ \\
\hline Pleurostachys regnellii C.B. Clarke $\square$ & et & $\mathrm{ma}$ & Regnell III 1319 (S) ** \\
\hline INDET.1 & es & $\mathrm{ca}$ & Rezende et al. $156^{*}$ \\
\hline INDET.2 & er & $\mathrm{ca}$ & Rezende et al. $31 *$ \\
\hline INDET.3 & et & $\mathrm{ca}$ & Rezende et al. $29 *$ \\
\hline \multicolumn{4}{|l|}{ DIOSCOREACEAE - 1/4 } \\
\hline Dioscorea adenocarpoides T. Clayton & li & $\mathrm{ca}$ & Regnell III 1242 (S) ** \\
\hline D. caldasensis R. Knuth & li & ma & Regnell III 1245 (S) ** \\
\hline D. de-mourae Uline ex R. Knuth & li & $\mathrm{ca}$ & Mosén $2545(\mathrm{~S}) * *$ \\
\hline D. ovata Vell. & li & $\mathrm{ca}$ & Monteiro et al. $469 *$ \\
\hline \multicolumn{4}{|l|}{ ELAEOCARPACEAE - 1/1 } \\
\hline Sloanea lasiocoma K. Schum. & av & $\mathrm{ma}$ & Lindberg $491(\mathrm{~S}) * *$ \\
\hline \multicolumn{4}{|c|}{ ERIOCAULACEAE - Marcelo Trovó L. Oliveira (SPF) - 2/2 } \\
\hline Eriocaulon regnellii Moldenke & et & $\mathrm{ca}$ & Regnell III $1740(\mathrm{~S}) * *$ \\
\hline Paepalanthus manicatus Pouls. ex Malme & es & $\mathrm{ca}$ & Rezende et al. $109 * * *$ \\
\hline \multicolumn{4}{|c|}{ ERYTHROXYLACEAE - Maria I. B. Loiola (EAC) - 1/2 } \\
\hline Erythroxylum amplifolium Baill. & av & bm & Machado et al. $160 *$ \\
\hline E. daphnites Mart. & av & $\mathrm{ca}, \mathrm{bm}$ & Rezende \& Elias $220 *$ \\
\hline \multicolumn{4}{|l|}{ EUPHORBIACEAE - 6/10 } \\
\hline Acalypha brasiliensis Müll. Arg. & et & $\mathrm{ca}$ & Rezende et al. $284 *$ \\
\hline A. gracilis Spreng. & et & bm & Machado et al. $168 * * *$ \\
\hline Alchornea triplinervia (Spreng.) Müll. Arg. & $a b$ & $\mathrm{ca}$ & Rezende et al. $164 * * *$ \\
\hline Croton eichleri Müll. Arg. & $a b$ & bm & Regnell II 242x (S) ** \\
\hline C. erythroxyloides Baill. & $a b$ & $\mathrm{bm}$ & Torres et al. 1613 (IAC) * \\
\hline C. floribundus Spreng. & av & bm & Rezende et al. $54 *$ \\
\hline C. migrans Casar. & $a b$ & $\mathrm{ca}$ & Rezende et al. $175 *$ \\
\hline
\end{tabular}

Espécies destacadas em negrito são aquelas citadas na lista de espécies ameaçadas da flora de Minas Gerais (Biodiversitas 2007): O "Criticamente em

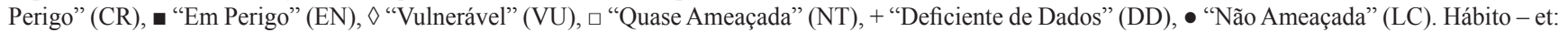
erva terrícola, ee: erva epífita, es: erva saxícola, er: erva rupícola, av: árvore, ab: arbusto, li - liana. Habitat - ca: campo de altitude, ma: interior de mata, bm: borda de mata, aa: área antrópica. Material testemunho: está citado um exemplar para cada espécie. * espécies coletadas apenas no presente estudo ou coletadas recentemente e depositadas nos acervos dos herbários analisados; ** espécies coletadas apenas por Regnell ou colaboradores no século XIX; *** espécies coletadas em ambos os casos.

Species in bold are those cited in the list of threatened species of Minas Gerais flora (Biodiversitas 2007): O "Critically endangered" (CR), " "Endangered" (EN), $\diamond$ "Vulnerable" (VU), $\square$ "Near Threatened" (NT), + "Data Defficient" (DD), • "Least Concern" (LC). Hábito - et: terrestrial herb, ee: epiphyte herb, es: saxicolous herb, er: rupicolous herb, av: tree, ab: shrub, li - liana. Habitat - ca: campo de altitude, ma: forest interior, bm: forest edge, aa: anthropic area. Material testemunho: one specimen is cited for each species. * species collected only on the present study or recently collected and deposited in the analyzed herbaria; ** species collected only by Regnell or collaborators in XIX century; *** species collected on both cases. 
Tabela 1. Continuação...

Table 1. Continued...

\begin{tabular}{|c|c|c|c|}
\hline Famílias/Espécies & Hábito & Habitat & Material testemunho \\
\hline Dalechampia regnellii Müll. Arg. & li & $\mathrm{ma}$ & Regnell III 1053 (S) ** \\
\hline Sapium glandulosum (L.) Morong & av & $\mathrm{ca}, \mathrm{bm}$ & Rezende \& Elias $249 *$ \\
\hline Sebastiania trichogyne Pax \& K. Hoffm. & $a b$ & $\mathrm{ca}$ & Mosén $716(\mathrm{~S}) * *$ \\
\hline \multicolumn{4}{|l|}{ FABACEAE - 13/26 } \\
\hline Bauhinia aculeata $\mathrm{L}$. & av & aa & Rezende \& Elias 256 * \\
\hline Camptosema ellipticum (Desv.) Burkart & li & $\mathrm{ca}$ & van den Berg 1288 (HUEFS) * \\
\hline C. scarlatinum (Benth.) Burkart & li & $\mathrm{ca}, \mathrm{ab}, \mathrm{aa}$ & Rezende et al. $92 *$ \\
\hline Cassia patellaria DC. ex Collad. & et & ca, aa & Rezende \& Elias $3 *$ \\
\hline Clitoria sp.1 & $a b$ & $\mathrm{ca}$ & Rezende et al. $67 *$ \\
\hline Clitoria sp.2 & li & ca & Gimenes et al. $4 *$ \\
\hline Collaea speciosa (Loisel.) DC. & at & $\mathrm{ca}, \mathrm{bm}, \mathrm{aa}$ & Elias et al. $37 *$ \\
\hline Desmodium purpureum Hook. \& Arn. & $a b$ & ca, aa & Gimenes et al. $6 *$ \\
\hline Inga vulpina Mart. ex Benth. & av & $\mathrm{bm}$ & Valente et al. $498 *$ \\
\hline Machaerium stipitatum Vogel & av & $\mathrm{ma}$ & Rezende $69(\mathrm{RB}) *$ \\
\hline M. villosum Vogel & av & $\mathrm{ca}, \mathrm{bm}$ & Rezende et al. $60 *$ \\
\hline Mimosa dolens Vell. & $a b$ & $\mathrm{ca}$ & Rezende $139(\mathrm{RB}) *$ \\
\hline M. furfuracea Hoehne & $a b$ & $\mathrm{ma}$ & Hoehne s.n. (SP 2878) * \\
\hline M. insidiosa Mart. & $a b$ & ca & Regnell I 92xx (S) ** \\
\hline M. pilulifera Benth. & $a b$ & ca & Hoehne s.n. (SP 2879) * \\
\hline M. cf. ramosissima Benth. & et & $\mathrm{ca}$ & Rezende \& Elias $270 *$ \\
\hline M. scabrella Benth. & av & $\mathrm{ma}$ & Ramos \& Conforti 236 (IAC) * \\
\hline Mimosa sp.1 & $a b$ & ca & Rezende et al. $139 *$ \\
\hline Mimosa sp.2 & $a b$ & bm & Elias et al. $31 *$ \\
\hline Platycyamus regnellii Benth. & av & bm & Rezende et al. $64 *$ \\
\hline Senna cernua (Balb.) H.S. Irwin \& Barneby & $a b$ & aa & Machado et al. $137 *$ \\
\hline S. pendula (Willd.) H.S.Irwin \& Barneby & $a b$ & ca & Rezende et al. $63 *$ \\
\hline S. splendida (Vogel) H.S.Irwin \& Barneby & $\mathrm{ab}$ & aa & Ramos \& Conforti 223 (IAC) * \\
\hline Senna sp. & $\mathrm{ab}$ & $\mathrm{ca}$ & Elias et al. $21 *$ \\
\hline Vigna sp. & li & $\mathrm{ca}, \mathrm{ma}$ & Rezende et al. $119 *$ \\
\hline Zornia diphylla (L.) Pers. & et & $\mathrm{ca}$ & Valente et al. $551 *$ \\
\hline \multicolumn{4}{|c|}{ GESNERIACEAE - Alain Chautems (G), Luciana C. Pereira (CESJ) - 1/5 } \\
\hline Sinningia aggregata (Ker Gawl.) Wiehler & et, er, es & $\mathrm{ca}$ & Rezende et al. $116^{*}$ \\
\hline S. allagophylla (Mart.) Wiehler & et & $\mathrm{ca}$ & Rezende \& Elias $221 *$ \\
\hline S. douglasii (Lindl.) Chautems & ee & ma & Valente et al. $504 *$ \\
\hline S. magnifica (Otto \& A. Dietr.) Wiehler & er, es & ca & Rezende \& Elias $12 *$ \\
\hline S. striata (Fritsch) Chautems $\diamond$ & er, es & ca & Rezende \& Elias $248 * * *$ \\
\hline \multicolumn{4}{|l|}{ HYPOXIDACEAE - 1/1 } \\
\hline Hypoxis decumbens L. & es & $\mathrm{ca}$ & Souza et al. $560 *$ \\
\hline \multicolumn{4}{|l|}{ IRIDACEAE - 4/5 } \\
\hline Calydorea campestris (Klatt) Baker & et & $\mathrm{ca}$ & Rezende et al. $146 *$ \\
\hline Cipura xanthomelas Mart. ex Klatt & et & ca, aa & Rezende et al. $69 *$ \\
\hline Sisyrinchium vaginatum Spreng. & es & $\mathrm{ca}$ & Rezende et al. $75 *$ \\
\hline Trimezia martinicensis (Jacq.) Herb. & et & ca & Machado et al. $146 *$ \\
\hline Trimezia sp. & es & $\mathrm{ca}$ & Monteiro et al. $465 *$ \\
\hline
\end{tabular}

Espécies destacadas em negrito são aquelas citadas na lista de espécies ameaçadas da flora de Minas Gerais (Biodiversitas 2007): $\mathrm{O}$ "Criticamente em

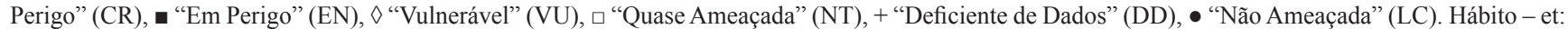
erva terrícola, ee: erva epífita, es: erva saxícola, er: erva rupícola, av: árvore, ab: arbusto, li - liana. Habitat - ca: campo de altitude, ma: interior de mata, bm: borda de mata, aa: área antrópica. Material testemunho: está citado um exemplar para cada espécie. * espécies coletadas apenas no presente estudo ou coletadas recentemente e depositadas nos acervos dos herbários analisados; ** espécies coletadas apenas por Regnell ou colaboradores no século XIX; *** espécies coletadas em ambos os casos.

Species in bold are those cited in the list of threatened species of Minas Gerais flora (Biodiversitas 2007): O "Critically endangered" (CR), " "Endangered" $(\mathrm{EN}), \diamond$ "Vulnerable" (VU), $\square$ "Near Threatened" (NT), + "Data Defficient" (DD), • "Least Concern” (LC). Hábito - et: terrestrial herb, ee: epiphyte herb, es: saxicolous herb, er: rupicolous herb, av: tree, ab: shrub, li - liana. Habitat - ca: campo de altitude, ma: forest interior, bm: forest edge, aa: anthropic area. Material testemunho: one specimen is cited for each species. * species collected only on the present study or recently collected and deposited in the analyzed herbaria; ** species collected only by Regnell or collaborators in XIX century; *** species collected on both cases. 
Tabela 1. Continuação...

Table 1. Continued..

\begin{tabular}{|c|c|c|c|}
\hline Famílias/Espécies & Hábito & Habitat & Material testemunho \\
\hline \multicolumn{4}{|l|}{ JUNCACEAE - 1/1 } \\
\hline Juncus cf. densiflorus Kunth. & et & ca & Rezende et al. $304 *$ \\
\hline \multicolumn{4}{|l|}{ LAMIACEAE - 5/11 } \\
\hline Aegiphila sellowiana Cham. & av & $\mathrm{ma}$ & Valente et al. $556^{*}$ \\
\hline Aegiphila sp. & av & $\mathrm{ca}$ & Rezende et al. $87 *$ \\
\hline Hyptis rugosa Benth. & $a b$ & ca & Rezende $204 *$ \\
\hline H. sidifolia (L'Herit.) Briq. & $a b$ & $\mathrm{bm}$ & van den Berg 1296 (HUEFS) * \\
\hline Ocimum gratissimum $\mathrm{L}$. & et & $\mathrm{ca}$ & Machado et al. $141 *$ \\
\hline Scutellaria sp. & es & ca, aa & Gimenes et al. $5 *$ \\
\hline Vitex polygama Cham. & av & $\mathrm{ca}, \mathrm{bm}, \mathrm{ma}$ & Rezende et al. $125 *$ \\
\hline INDET.1 & et & $\mathrm{ca}$ & Rezende et al. $120 *$ \\
\hline INDET.2 & et & $\mathrm{ca}$ & Rezende et al. $365^{*}$ \\
\hline INDET.3 & at & $\mathrm{bm}$ & Rezende \& Elias $224 *$ \\
\hline INDET.4 & at & aa & Rezende \& Elias $204 *$ \\
\hline \multicolumn{4}{|c|}{ LAURACEAE - Leandro C. S. Assis (BHCB) - 2/5 } \\
\hline Endlicheria paniculata (Spreng.) J.F. Macbr. & av & $\mathrm{bm}$ & Rezende et al. $132 *$ \\
\hline Ocotea corymbosa (Meisn.) Mez & av & $\mathrm{ma}$ & Regnell III $76(\mathrm{~S}) * *$ \\
\hline O. frondosa (Meisn.) Mez + & av & $\mathrm{ma}$ & Regnell III $80(\mathrm{~S}) * *$ \\
\hline O. pulchella (Nees) Mez & $\mathrm{ab}$ & $\mathrm{ca}$ & Rezende et al. $94 *$ \\
\hline INDET. & at & $\mathrm{ma}$ & Rezende \& Elias $226^{*}$ \\
\hline \multicolumn{4}{|l|}{ LENTIBULARIACEAE - 2/2 } \\
\hline Genlisea violacea A. St. -Hil & et, es & $\mathrm{ca}$ & Rezende et al. $147 * * *$ \\
\hline Utricularia warmingii Kamienski & et, es & $\mathrm{ca}$ & Rezende et al. $114 *$ \\
\hline \multicolumn{4}{|l|}{ LOGANIACEAE - 1/1 } \\
\hline Strychnos brasiliensis (Spreng.) Mart. & av & $\mathrm{ca}$ & Elias et al. $39 *$ \\
\hline \multicolumn{4}{|l|}{ LYTHRACEAE - 2/2 } \\
\hline Cuphea sp. & et & $\mathrm{ca}$ & Monteiro et al. $485 *$ \\
\hline Lafoensia pacari A.St.-Hil. & av & ca, aa & Rezende et al. $52 *$ \\
\hline \multicolumn{4}{|l|}{ MAGNOLIACEAE - 1/1 } \\
\hline Magnolia ovata (A.St.-Hil.) Spreng. & av & $\mathrm{bm}$ & Rezende et al. $102 *$ \\
\hline \multicolumn{4}{|l|}{ MALPIGHIACEAE - 4/9 } \\
\hline Banisteriopsis adenopoda (A. Juss.) B.Gates & li & $\mathrm{bm}$ & Sem coletor $($ MO 100183889) * \\
\hline B. campestris (A. Juss.) Little & li & aa & Souza et al. $649 *$ \\
\hline B. laevifolia (A. Juss.) B. Gates & $a b$ & $a b$ & Rezende et al. $329 *$ \\
\hline Bunchosia pallescens Skottsb. & av & $\mathrm{ma}$ & Regnell III 1537 (S) ** \\
\hline Byrsonima pachyphylla A. Juss. & av & $\mathrm{ca}$ & Regnell II $31(\mathrm{~S}) * *$ \\
\hline Heteropterys syringifolia Griseb. & - & - & Regnell I 31 (S) ** \\
\hline Heteropterys umbellata A. Juss. & $a b$ & $\mathrm{ca}$ & Rezende et al. $328 *$ \\
\hline Heteropterys sp. & av & $\mathrm{bm}$ & Rezende et al. $103 *$ \\
\hline INDET. & av & $\mathrm{bm}$ & Rezende et al. $140 *$ \\
\hline \multicolumn{4}{|c|}{ MALVACEAE - Aluísio J. Fernandes Júnior (CESJ) - 8/11 } \\
\hline Ceiba speciosa (A.St.-Hil.) Ravenna & av & aa & Machado et al. $135 *$ \\
\hline Luehea candicans Mart. & av & $\mathrm{bm}$ & Rezende et al. $59 *$ \\
\hline L. grandiflora Mart. \& Zucc. & av & bm & Rezende et al. $136 *$ \\
\hline
\end{tabular}

Espécies destacadas em negrito são aquelas citadas na lista de espécies ameaçadas da flora de Minas Gerais (Biodiversitas 2007): O "Criticamente em

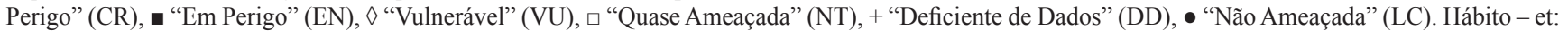
erva terrícola, ee: erva epífita, es: erva saxícola, er: erva rupícola, av: árvore, ab: arbusto, li - liana. Habitat - ca: campo de altitude, ma: interior de mata, bm: borda de mata, aa: área antrópica. Material testemunho: está citado um exemplar para cada espécie. * espécies coletadas apenas no presente estudo ou coletadas recentemente e depositadas nos acervos dos herbários analisados; ** espécies coletadas apenas por Regnell ou colaboradores no século XIX; *** espécies coletadas em ambos os casos.

Species in bold are those cited in the list of threatened species of Minas Gerais flora (Biodiversitas 2007): O "Critically endangered" (CR), " "Endangered" (EN), $\diamond$ "Vulnerable" (VU), $\square$ "Near Threatened" (NT), + "Data Defficient" (DD), • "Least Concern" (LC). Hábito - et: terrestrial herb, ee: epiphyte herb, es: saxicolous herb, er: rupicolous herb, av: tree, ab: shrub, li - liana. Habitat - ca: campo de altitude, ma: forest interior, bm: forest edge, aa: anthropic area. Material testemunho: one specimen is cited for each species. * species collected only on the present study or recently collected and deposited in the analyzed herbaria; ** species collected only by Regnell or collaborators in XIX century; *** species collected on both cases. 
Tabela 1. Continuação...

Table 1. Continued...

\begin{tabular}{|c|c|c|c|}
\hline Famílias/Espécies & Hábito & Habitat & Material testemunho \\
\hline Pavonia communis A.St-Hil. & $\mathrm{ab}$ & aa & Machado et al. $127 *$ \\
\hline P. sagittata A. St.-Hil. & $a b$ & $\mathrm{ca}$ & Regnell III $174(\mathrm{~S}) * *$ \\
\hline Peltaea sp. & es & $\mathrm{ca}$ & Rezende \& Elias $4 *$ \\
\hline Pseudobombax longiflorum (Mart. \& Zucc.) A. Robyns & av & $\mathrm{ca}$ & Regnell I 23 (S) ** \\
\hline Sida rhombifolia $\mathrm{L}$. & et & aa & Machado et al. $143 *$ \\
\hline Triumfetta semitriloba Jacq. & et & aa & Ramos \& Conforti 240 (IAC) * \\
\hline Wissadula parviflora (A.St.-Hil.) R.E.Fr. & et & aa & Krapovickas $35471(\mathrm{NY}) *$ \\
\hline INDET. & et & aa & Machado et al. $140 *$ \\
\hline \multicolumn{4}{|c|}{ MELASTOMATACEAE - Renato Goldenberg (UPCB), Rosana Romero (HUFU) - 4/14 } \\
\hline Leandra regnellii (Triana) Cogn. & $a b$ & ma & Mosén $493(\mathrm{~S}) * *$ \\
\hline Miconia cinerascens Miq. & $a b$ & bm, ma & Rezende et al. $62 *$ \\
\hline M. pusilliflora (DC.) Naudin & av & ma & Rezende et al. $101 *$ \\
\hline M. theaezans (Bonpl.) Cogn. & av & ma & Hoehne s.n. (SP 2877) * \\
\hline Microlepis mosenii Cogn. + & $\mathrm{ab}$ & $\mathrm{ca}$ & Regnell I $155(\mathrm{~S}) * *$ \\
\hline Tibouchina clidemioides (Triana) Cogn. & et & $\mathrm{ca}$ & Rezende et al. $160 *$ \\
\hline T. fothergillae (DC.) Cogn. & er & ma & Elias et al. $33 *$ \\
\hline T. gracilis (Bonpl.) Cogn. & et & aa & Machado et al. $103 *$ \\
\hline T. heteromalla (D. Don) Cogn. & $a b$ & $\mathrm{ca}$ & Rezende et al. $126 *$ \\
\hline T. martialis (Cham.) Cogn. & $a b$ & ca, aa & Rezende et al. $130 *$ \\
\hline T. mosenii Cogn. & $a b$ & $\mathrm{ca}$ & Mosén $1972(\mathrm{~S}) * *$ \\
\hline T. regnellii Cogn. & $a b$ & $\mathrm{ca}$ & Regnell III 1763 (S) ** \\
\hline T. sellowiana Cogn. & av & ma & Sem coletor (MO 1002240620) ** \\
\hline Tibouchina sp. & av & $\mathrm{ca}$ & Rezende et al. $197 *$ \\
\hline \multicolumn{4}{|l|}{ MELIACEAE - 2/2 } \\
\hline Cabralea canjerana (Vell.) Mart. & av & aa & Rezende et al. $349 *$ \\
\hline Trichilia elegans A. Juss. & av & $\mathrm{ca}$ & Rezende et al. $57 *$ \\
\hline \multicolumn{4}{|l|}{ MONIMIACEAE - 2/3 } \\
\hline Macropeplus cf. dentatus (Perkins) I. Santos \& Peixoto & av & $\mathrm{bm}$ & Valente et al. $496 *$ \\
\hline Mollinedia schottiana (Spreng.) Perkins & av & bm & Machado et al. $155 *$ \\
\hline M. widgrenii A. DC. & av & bm, ma & Rezende $83 *$ \\
\hline \multicolumn{4}{|l|}{ MORACEAE - 1/1 } \\
\hline Sorocea bonplandii (Baill.) W.C. Burger, Lanj. \& Bôer & av & $\mathrm{ma}$ & Valente et al. $499 *$ \\
\hline \multicolumn{4}{|l|}{ MYRTACEAE - Marcos Sobral (UFSJ) - 7/12 } \\
\hline Campomanesia guazumifolia (Cambess.) O.Berg & av & ma & Regnell II 118 (S) ** \\
\hline C. pubescens (DC.) O.Berg & av & ca & Rezende $219 *$ \\
\hline Campomanesia sp. & $a b$ & ca & Rezende et al. $198 *$ \\
\hline Eugenia involucrata DC. & av & $\mathrm{bm}$ & Rezende \& Elias $279 *$ \\
\hline Myrcia obovata (O. Berg) Nied. & $a b$ & $\mathrm{ca}$ & Rezende \& Elias $255 *$ \\
\hline M. splendens (SW.) DC. & $a b$ & $\mathrm{ca}, \mathrm{bm}, \mathrm{aa}$ & Rezende et al. $176^{*}$ \\
\hline Myrciaria floribunda (H. West ex Willd.) O. Berg & av & ma & Rezende et al. $192 *$ \\
\hline Pimenta pseudocaryophyllus (Gomes) Landrum & av & bm & Rezende et al. $82 *$ \\
\hline Psidium guajava $\mathrm{L}$. & av & aa & Machado et al. $132 *$ \\
\hline P. rufum Mart ex DC. & $a b$ & ma & Ramos \& Conforti 239 (IAC) *** \\
\hline Siphoneugena widgreniana O. Berg & av & $\mathrm{bm}$ & Rezende et al. $86^{*}$ \\
\hline
\end{tabular}

Espécies destacadas em negrito são aquelas citadas na lista de espécies ameaçadas da flora de Minas Gerais (Biodiversitas 2007): O "Criticamente em

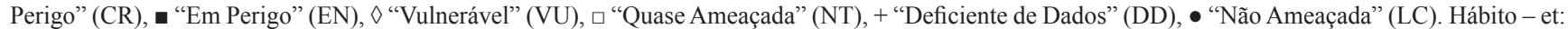
erva terrícola, ee: erva epífita, es: erva saxícola, er: erva rupícola, av: árvore, ab: arbusto, li - liana. Habitat - ca: campo de altitude, ma: interior de mata, bm: borda de mata, aa: área antrópica. Material testemunho: está citado um exemplar para cada espécie. * espécies coletadas apenas no presente estudo ou coletadas recentemente e depositadas nos acervos dos herbários analisados; ** espécies coletadas apenas por Regnell ou colaboradores no século XIX; *** espécies coletadas em ambos os casos.

Species in bold are those cited in the list of threatened species of Minas Gerais flora (Biodiversitas 2007): O "Critically endangered" (CR), " "Endangered" $(E N), \diamond$ "Vulnerable" (VU), ๑ "Near Threatened" (NT), + "Data Defficient" (DD), • "Least Concern" (LC). Hábito - et: terrestrial herb, ee: epiphyte herb, es: saxicolous herb, er: rupicolous herb, av: tree, ab: shrub, li - liana. Habitat - ca: campo de altitude, ma: forest interior, bm: forest edge, aa: anthropic area. Material testemunho: one specimen is cited for each species. * species collected only on the present study or recently collected and deposited in the analyzed herbaria; ** species collected only by Regnell or collaborators in XIX century; *** species collected on both cases. 
Tabela 1. Continuação...

Table 1. Continued...

\begin{tabular}{|c|c|c|c|}
\hline Famílias/Espécies & Hábito & Habitat & Material testemunho \\
\hline INDET. & av & $\mathrm{bm}$ & Rezende et al. $84 *$ \\
\hline \multicolumn{4}{|l|}{ NYCTAGINACEAE - 1/1 } \\
\hline Guapira sp. & av & $\mathrm{ca}$ & Torres et al. $1914 *$ \\
\hline \multicolumn{4}{|l|}{ ONAGRACEAE - 1/1 } \\
\hline Fuchsia regia (Vell.) Munz & et & $\mathrm{bm}$ & Elias et al. $35 *$ \\
\hline \multicolumn{4}{|l|}{ OPILIACEAE - Ronaldo Marquete (RB) - 1/1 } \\
\hline Agonandra excelsa Griseb. & av & aa & Rezende \& Elias $209 *$ \\
\hline \multicolumn{4}{|c|}{ ORCHIDACEAE - Luiz Menini Neto (CESJ), Narjara L. Abreu (CESJ), Cláudio N. Fraga (RB) - 28/56 } \\
\hline Bifrenaria harrisoniae (Hook.) Rchb. f. & er & $\mathrm{ca}$ & Souza et al. $539 *$ \\
\hline Brassavola tuberculata Hook. & er & $\mathrm{ca}$ & Rezende et al. $345 *$ \\
\hline Bulbophyllum epiphytum Barb. Rodr. & er & $\mathrm{ca}$ & Rezende et al. $202 *$ \\
\hline B. exaltatum Lindl. & ee, er & ca, aa & Rezende et al. $26 *$ \\
\hline B. plumosum (Barb. Rodr.) Cogn. & er & $\mathrm{ca}$ & Souza et al. $656^{*}$ \\
\hline Capanemia superflua (Rchb. f.) Garay & ee & $\mathrm{ma}$ & Regnell III 1168 (S) ** \\
\hline Cyclopogon cf. congestus (Vell.) Hoehne & er & $\mathrm{ca}$ & Machado et al. $85 *$ \\
\hline C. graciliscapus Schltr. & et & $\mathrm{ma}$ & Regnell III 1196B (S) ** \\
\hline C. longibracteatus (Barb. Rodr.) Schltr. & et & $\mathrm{ca}$ & Rezende et al. $370 *$ \\
\hline C. cf. truncatus (Lindl.) Schltr. & et & ma & Rezende et al. $368 *$ \\
\hline Cyclopogon sp. & et & $\mathrm{bm}$ & Souza et al. $552 *$ \\
\hline Epidendrum avicula Lindl. & er & $\mathrm{ca}$ & Machado et al. $99 *$ \\
\hline Epidendrum chlorinum Barb. Rodr. & ee & $\mathrm{ma}$ & van den Berg 1049 (HUEFS) * \\
\hline E. mantiqueiranum Porto \& Brade & ee & ma & van den Berg 1280 (HUEFS) * \\
\hline E. minarum Hoehne \& Schltr. & et & $\mathrm{ca}$ & Hoehne s.n. (SP 2876) * \\
\hline E. secundum Jacq. & et, er, es & $\mathrm{ca}$ & Rezende et al. $89 *$ \\
\hline Govenia utriculata (Sw.) Lindl. & et & $\mathrm{ma}$ & Rezende et al. $299 *$ \\
\hline Habenaria caldensis Kraenzl. & et & $\mathrm{ca}$ & Regnell III 1181 (S) ** \\
\hline H. macronectar (Vell.) Hoehne & er & $\mathrm{ca}$ & Rezende \& Elias $280 *$ \\
\hline H. regnellii Cogn. & et & $\mathrm{ca}$ & Regnell III $1182(\mathrm{~S}) * *$ \\
\hline H. rupicola Barb. Rodr. & et & $\mathrm{ca}$ & van den Berg 1279 (HUEFS) * \\
\hline Habenaria sp. & es & $\mathrm{ca}$ & Monteiro et al. $461 *$ \\
\hline Hapalorchis lineatus (Lindl.) Schltr. & et & $\mathrm{ma}$ & Mosén $746(\mathrm{~S}) * *$ \\
\hline H. micranthus (Barb. Rodr.) Hoehne & et & $\mathrm{ma}$ & van den Berg 1841 (HUEFS) * \\
\hline Isochilus linearis (Jacq.) R.Br. & ee & ma, aa & Rezende et al. $23 *$ \\
\hline Malaxis sp. & et & ma & van den Berg 1284 (HUEFS) * \\
\hline Maxillaria chrysantha Barb. Rodr. & ee & ma & Regnell 426A (SP) ** \\
\hline M. picta Hook. & er & $\mathrm{ca}$ & Elias et al. $40 *$ \\
\hline Nemaconia striata (Lindl.) van den Berg, Salazar \& Soto Arenas & ee & ma & Regnell III $1153(\mathrm{~S}) * *$ \\
\hline Notylia longispicata Hoehne \& Schltr. & ee & aa & Machado et al. $151 *$ \\
\hline Octomeria albiflora Hoehne \& Schltr. & ee & ma & Hoehne s.n. (SP 2887) * \\
\hline Oncidium blanchetii Rchb. f. & et & $\mathrm{ca}$ & Batista et al. $2784(\mathrm{BHCB}) *$ \\
\hline O. longipes Lindl. & ee & $\mathrm{ma}$ & van den Berg 1964 (HUEFS) * \\
\hline O. ramosum Lindl. & er & $\mathrm{ca}$ & Rezende et al. $283 *$ \\
\hline O. varicosum Lindl. \& Paxton & ee, et & $\mathrm{ca}$ & Rezende et al. $32 *$ \\
\hline Pelexia bonariensis (Lindl.) Schltr. & es & $\mathrm{ca}$ & Regnell III 2007 (S) ** \\
\hline
\end{tabular}

Espécies destacadas em negrito são aquelas citadas na lista de espécies ameaçadas da flora de Minas Gerais (Biodiversitas 2007): O "Criticamente em

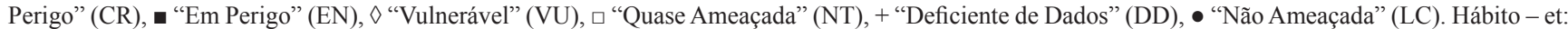
erva terrícola, ee: erva epífita, es: erva saxícola, er: erva rupícola, av: árvore, ab: arbusto, li - liana. Habitat - ca: campo de altitude, ma: interior de mata, bm: borda de mata, aa: área antrópica. Material testemunho: está citado um exemplar para cada espécie. * espécies coletadas apenas no presente estudo ou coletadas recentemente e depositadas nos acervos dos herbários analisados; ** espécies coletadas apenas por Regnell ou colaboradores no século XIX; *** espécies coletadas em ambos os casos.

Species in bold are those cited in the list of threatened species of Minas Gerais flora (Biodiversitas 2007): O "Critically endangered" (CR), घ "Endangered"

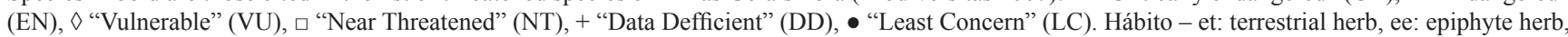
es: saxicolous herb, er: rupicolous herb, av: tree, ab: shrub, li - liana. Habitat - ca: campo de altitude, ma: forest interior, bm: forest edge, aa: anthropic area. Material testemunho: one specimen is cited for each species. * species collected only on the present study or recently collected and deposited in the analyzed herbaria; ** species collected only by Regnell or collaborators in XIX century; *** species collected on both cases. 
Tabela 1. Continuação...

Table 1. Continued...

\begin{tabular}{|c|c|c|c|}
\hline Famílias/Espécies & Hábito & Habitat & Material testemunho \\
\hline P. novofriburgensis (Rchb. f.) Garay & et & $\mathrm{ma}$ & Rodrigues $1168(\mathrm{~S}) * *$ \\
\hline Pelexia sp. & er & $\mathrm{ca}$ & Elias et al. $30 *$ \\
\hline Pleurothallis fenestrata Barb. Rodr. & ee & ma & Regnell III 1676 bis (S) ** \\
\hline P. grobyi Lindl. & es & ma & Regnell III 1129 (S) ** \\
\hline P. klotzschiana Rchb. f. & ee & ma & Regnell II 273 (S) ** \\
\hline$P$. recurva Lindl. & ee & bm & Rezende \& Elias $281 *$ \\
\hline P. rubens Lindl. & ee & ma & Rezende \& Elias $263 *$ \\
\hline P. saurocephala Lodd. & ee & ma & Rezende et al. $65 *$ \\
\hline Polystachya pinicola Barb. Rodr. & ee & ma & Regnell III 1145 (S) ** \\
\hline Prescottia montana Barb. Rodr. & et & ca & Azevedo 324 (HUEFS) * \\
\hline Prosthechea allemanoides (Hoehne) W.E. Higgins & ee & $\mathrm{ca}$ & Rezende et al. $200 *$ \\
\hline P. regnelliana (Hoehne \& Schltr.) W.E.Higgins & ee & ma & Hoehne 4320 (SP) * \\
\hline Pteroglossa macrantha (Rchb. f.) Schltr. & et & $\mathrm{ca}$ & Regnell III 1198 (S) ** \\
\hline Sacoila lanceolata (Aubl.) Garay & et & $\mathrm{ca}$ & Rezende et al. $188 * *$ \\
\hline Skeptrostachys paraguayensis (Rchb. f.) Garay & et & $\mathrm{ca}$ & Regnell III 1194 (S) ** \\
\hline Stelis aprica Lindl. & ee & ma & Regnell I $423(\mathrm{~S}) * *$ \\
\hline Stigmatosema polyaden (Vell.) Garay & et & $\mathrm{ca}$ & Rezende et al. $201 *$ \\
\hline Zygopetalum mackayi Hook. & er & $\mathrm{ca}$ & Souza et al. $537 *$ \\
\hline Z. triste Barb. Rodr. $\square$ & et & $\mathrm{ca}$ & van den Berg 1797 (HUEFS) * \\
\hline \multicolumn{4}{|l|}{ OROBANCHACEAE - 1/1 } \\
\hline Escobedia grandiflora (L.f.) Kuntze & et & $\mathrm{ca}$ & Rezende et al. $129 *$ \\
\hline \multicolumn{4}{|l|}{ OXALIDACEAE - 1/2 } \\
\hline Oxalis rupestris A.St.-Hil. & et & $\mathrm{ca}$ & Regnell I 43 (S) ** \\
\hline O. tetraphylla Cav. & et & $\mathrm{ca}$ & Rezende \& Elias $273 *$ \\
\hline \multicolumn{4}{|c|}{ PASSIFLORACEAE - Ana Carolina Mezzonato (CESJ), Luís Carlos Bernacci (BHCB) - 2/6 } \\
\hline Passiflora alata Curtis & li & $\mathrm{ca}$ & Rezende et al. $93 *$ \\
\hline P. caerulea L. & li & $\mathrm{bm}$ & Regnell III 636 (S) ** \\
\hline P. capsularis L. & li & aa & Machado et al. $126 *$ \\
\hline P. organensis Gardner & li & ca & Machado et al. $111 *$ \\
\hline P. suberosa L. & li & aa & Machado et al. $134 *$ \\
\hline Turnera hilaireana Urb. & $a b$ & $\mathrm{ca}$ & Regnell I $100(\mathrm{~S}) * *$ \\
\hline \multicolumn{4}{|c|}{ PHYLLANTHACEAE - Maria Iracema Bezerra Loiola (EAC) - 1/3 } \\
\hline Phyllanthus dictyospermus Müll. Arg. & et & $\mathrm{ca}$ & Regnell II 48 (S) ** \\
\hline P. niruri L. & et & ca & Hoehne s.n. (SP 2892) * \\
\hline P. stipitatus M.Schmid & et & $\mathrm{ca}$ & Rezende et al. $166 *$ \\
\hline \multicolumn{4}{|l|}{ PHYTOLACCACEAE - 1/1 } \\
\hline Phytolacca sp. & $\mathrm{ab}$ & aa & Machado et al. $107 *$ \\
\hline \multicolumn{4}{|l|}{ PIPERACEAE - Daniele Monteiro (RB) - 2/19 } \\
\hline Peperomia augescens Miq. & ee, er, es & $\mathrm{ca}, \mathrm{bm}$ & Rezende et al. $47 * * *$ \\
\hline P. blanda (Jacq.) Kunth & ee & ca, aa & Souza et al. $666^{*}$ \\
\hline P. corcovadensis Gardner & ee & ma & Rezende et al. $190 * * *$ \\
\hline$P$. galioides Kunth & ee, et, er & $\mathrm{ca}, \mathrm{ma}$ & Rezende et al. $36 *$ \\
\hline P. hilariana Miq. & et & ma & Monteiro et al. $487 *$ \\
\hline P. loxensis Kunth & ee & ma & Lindberg $485(\mathrm{NY}) * *$ \\
\hline
\end{tabular}

Espécies destacadas em negrito são aquelas citadas na lista de espécies ameaçadas da flora de Minas Gerais (Biodiversitas 2007): O "Criticamente em

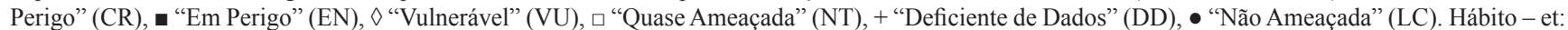
erva terrícola, ee: erva epífita, es: erva saxícola, er: erva rupícola, av: árvore, ab: arbusto, li - liana. Habitat - ca: campo de altitude, ma: interior de mata, bm: borda de mata, aa: área antrópica. Material testemunho: está citado um exemplar para cada espécie. * espécies coletadas apenas no presente estudo ou coletadas recentemente e depositadas nos acervos dos herbários analisados; ** espécies coletadas apenas por Regnell ou colaboradores no século XIX; *** espécies coletadas em ambos os casos.

Species in bold are those cited in the list of threatened species of Minas Gerais flora (Biodiversitas 2007): O "Critically endangered" (CR), "Endangered" $(\mathrm{EN}), \diamond$ "Vulnerable" (VU), $\square$ "Near Threatened" (NT), + "Data Defficient” (DD), • "Least Concern” (LC). Hábito - et: terrestrial herb, ee: epiphyte herb, es: saxicolous herb, er: rupicolous herb, av: tree, ab: shrub, li - liana. Habitat - ca: campo de altitude, ma: forest interior, bm: forest edge, aa: anthropic area. Material testemunho: one specimen is cited for each species. * species collected only on the present study or recently collected and deposited in the analyzed herbaria; ** species collected only by Regnell or collaborators in XIX century; *** species collected on both cases. 
Tabela 1. Continuação...

Table 1. Continued...

\begin{tabular}{|c|c|c|c|}
\hline Famílias/Espécies & Hábito & Habitat & Material testemunho \\
\hline P. oreophila Henschen & er, es & $\mathrm{ca}$ & Monteiro et al. $459 * * *$ \\
\hline P. tetraphylla (G. Forst.) Hook. \& Arn. & ee, er, es & $\mathrm{ca}, \mathrm{ma}$ & Rezende et al. $150 *$ \\
\hline P. trineura Miq. & ee & $\mathrm{ca}, \mathrm{ma}$ & Rezende et al. $104 *$ \\
\hline Piper arboreum Aubl. & et & $\mathrm{ma}$ & Rezende et al. $359 *$ \\
\hline P. caldense C.DC. & $a b$ & $\mathrm{ma}$ & Mosén $735(\mathrm{~S}) * *$ \\
\hline P. chimonanthifolium Kunth. & $\mathrm{ab}$ & bm & Rezende et al. $358 *$ \\
\hline P. crassinervium Kunth & av & $\mathrm{bm}$ & Elias et al. $24 *$ \\
\hline P. divaricatum G. Mey & $a b$ & $\mathrm{ma}$ & Regnell III 1114 (S) ** \\
\hline P. gaudichaudianum Kunth & $a b$ & $\mathrm{ca}$ & Rezende et al. $184 *$ \\
\hline P. lucaeanum Kunth & $\mathrm{ab}$ & ma & Mosén $1026(\mathrm{NY}) * *$ \\
\hline P. regnellii (Miq.) C. DC & $a b$ & bm, aa & Rezende et al. $98 * * *$ \\
\hline P. schenckii C. DC. & li & ma & Rezende et al. $194 *$ \\
\hline P. solmsianum C. DC. & $\mathrm{ab}$ & ma & Monteiro et al. $488 *$ \\
\hline \multicolumn{4}{|c|}{ POACEAE - Fabrício M. Ferreira (HUEFS), Pedro L. Viana (BHCB) - 8/12 } \\
\hline Andropogon bicornis L. & et & $\mathrm{ca}$ & Rezende et al. $312 *$ \\
\hline Chusquea meyeriana Rupr. & et & $\mathrm{ma}$ & Clark 841 (HSJRP) * \\
\hline Dichanthelium stigmosum (Trin.) Zuloaga & et & $\mathrm{ca}$ & Rezende et al. $38 *$ \\
\hline Eragrostis apiculata Döll & et & $\mathrm{ca}$ & Regnell III $1411(\mathrm{~S}) * *$ \\
\hline E. polytricha Nees & et & $\mathrm{ca}$ & Regnell III 1405 (S) ** \\
\hline Panicum cf. cyanescens Nees ex Trin. & et, es & $\mathrm{ca}$ & Rezende et al. $76^{*}$ \\
\hline P. exiguum $\mathrm{Mez}$ & et & $\mathrm{ca}$ & Mosén s.n. (US623.2144933) ** \\
\hline Paspalum rupium Renvoize & et & $\mathrm{ca}$ & Rezende et al. $79 *$ \\
\hline Setaria sphacelata Stapf \& C.E.Hubb. ex M.B.Moss & et & $\mathrm{ca}$ & Rezende \& Elias $246 * * *$ \\
\hline S. vulpiseta (Lam.) Roem. \& Schult. & et & ca, aa & Machado et al. $145 *$ \\
\hline Sporobolus indicus (L.) R. Br. & et & $\mathrm{ca}$ & Rezende et al. $124 *$ \\
\hline S. metallicolus Longhi-Wagner \& Boechat & et & ca & Rezende et al. $305 *$ \\
\hline \multicolumn{4}{|l|}{ POLYGALACEAE - 2/2 } \\
\hline Bredemeyera sp. & et & aa & Rezende \& Elias $216^{*}$ \\
\hline Polygala paniculata $\mathrm{L}$. & et, es & $\mathrm{ca}$ & Rezende et al. $110 *$ \\
\hline \multicolumn{4}{|l|}{ PRIMULACEAE $-2 / 5$} \\
\hline Anagallis alternifolia Cav. & et, er & ca & Rezende et al. $112 *$ \\
\hline Myrsine guianensis (Aubl.) Kuntze & av & $\mathrm{ca}$ & Rezende et al. $24 *$ \\
\hline M. lancifolia Mart. & av & bm, ma & Elias et al. $34 *$ \\
\hline M. loefgrenii (Mez) Otegui & av & $\mathrm{bm}$ & Mosén $1895(\mathrm{~S}) * *$ \\
\hline INDET. & $a b$ & $\mathrm{bm}$ & Monteiro et al. $466^{*}$ \\
\hline \multicolumn{4}{|l|}{ PROTEACEAE - 1/1 } \\
\hline Roupala montana Aubl. & av & $\mathrm{ma}$ & Rezende et al. $117 *$ \\
\hline \multicolumn{4}{|l|}{ ROSACEAE - 2/3 } \\
\hline Prunus myrtifolia (L.) Urb. & av & ca & Rezende et al. $56 *$ \\
\hline P. reflexa Walp. & av & $\mathrm{ma}$ & Krapovickas $35473(\mathrm{NY}) *$ \\
\hline Rubus brasiliensis Mart. & $\mathrm{ab}$ & $\mathrm{ca}$ & Rezende \& Elias $203 *$ \\
\hline \multicolumn{4}{|l|}{ RUBIACEAE - Juliana Oliveira (CESJ) - 11/17 } \\
\hline Borreria verticillata (L.) G. Mey. & et & $\mathrm{ca}$ & Rezende \& Elias $231 *$ \\
\hline Chiococca alba (L.) Hitchc. & $\mathrm{ab}$ & ca, aa & Monteiro et al. $479 *$ \\
\hline
\end{tabular}

Espécies destacadas em negrito são aquelas citadas na lista de espécies ameaçadas da flora de Minas Gerais (Biodiversitas 2007): O "Criticamente em

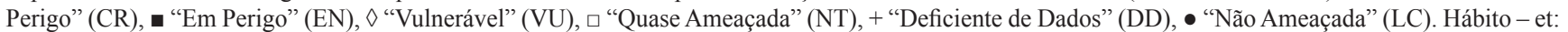
erva terrícola, ee: erva epífita, es: erva saxícola, er: erva rupícola, av: árvore, ab: arbusto, li - liana. Habitat - ca: campo de altitude, ma: interior de mata, bm: borda de mata, aa: área antrópica. Material testemunho: está citado um exemplar para cada espécie. * espécies coletadas apenas no presente estudo ou coletadas recentemente e depositadas nos acervos dos herbários analisados; ** espécies coletadas apenas por Regnell ou colaboradores no século XIX; *** espécies coletadas em ambos os casos.

Species in bold are those cited in the list of threatened species of Minas Gerais flora (Biodiversitas 2007): O "Critically endangered" (CR), " "Endangered" $(\mathrm{EN}), \diamond$ "Vulnerable" (VU), $\square$ "Near Threatened" (NT), + "Data Defficient" (DD), • "Least Concern" (LC). Hábito - et: terrestrial herb, ee: epiphyte herb, es: saxicolous herb, er: rupicolous herb, av: tree, ab: shrub, li - liana. Habitat - ca: campo de altitude, ma: forest interior, bm: forest edge, aa: anthropic area. Material testemunho: one specimen is cited for each species. * species collected only on the present study or recently collected and deposited in the analyzed herbaria; ** species collected only by Regnell or collaborators in XIX century; *** species collected on both cases. 
Tabela 1. Continuação...

Table 1. Continued...

\begin{tabular}{|c|c|c|c|}
\hline Famílias/Espécies & Hábito & Habitat & Material testemunho \\
\hline Chomelia obtusa Cham. \& Schltdl. & av & $\mathrm{bm}$ & Machado et al. $161 *$ \\
\hline Chomelia sp. & av & $\mathrm{bm}$ & Machado et al. $162 *$ \\
\hline Coccocypselum lanceolatum (Ruiz \& Pav.) Pers. & et & $\mathrm{ca}$ & Rezende \& Elias 247 * \\
\hline Faramea hyacinthina Mart. & $a b$ & ca, aa & Rezende et al. $292 *$ \\
\hline Galianthe valerianoides (Cham. \& Schltdl.) E.L. Cabral & et & $\mathrm{ca}$ & Rezende \& Elias $253 *$ \\
\hline Galium megapotamicum Spreng. & et & $\mathrm{ca}$ & Regnell I 173d (S) ** \\
\hline Guettarda angelica Mart. ex Müll. Arg. & av & $\mathrm{bm}$ & Rezende \& Elias 233 * \\
\hline G. viburnoides Cham. \& Schltdl. & av & $\mathrm{ca}, \mathrm{ma}$ & Rezende et al. $317 *$ \\
\hline Manettia cordifolia Mart. & et & $\mathrm{ca}, \mathrm{bm}$ & Rezende et al. $300 *$ \\
\hline M. luteo-rubra (Vell.) Benth. & li & aa & Souza et al. $650 *$ \\
\hline Psychotria dusenii Standl. & av & ma & Valente et al. $502 *$ \\
\hline P. leiocarpa Cham. \& Schltdl. & $a b$ & bm & Monteiro et al. $472 *$ \\
\hline P. vellosiana Benth. & av & $\mathrm{bm}$ & Rezende et al. $311 *$ \\
\hline Rudgea gardenioides (Cham.) Müll. Arg. & av & ma & Rezende et al. $97 *$ \\
\hline R. jasminoides (Cham.) Müll. Arg. & $a b$ & ma & Rezende et al. $335 * * *$ \\
\hline \multicolumn{4}{|l|}{ RUTACEAE - 1/1 } \\
\hline Zanthoxylum sp. & $a b$ & $\mathrm{ca}$ & Rezende et al. $170 *$ \\
\hline \multicolumn{4}{|l|}{ SALICACEAE - $2 / 4$} \\
\hline Casearia decandra Jacq. & $a b$ & $\mathrm{ca}, \mathrm{bm}$ & Rezende et al. $171 *$ \\
\hline C. lasiophylla Eichler & av & $\mathrm{bm}$ & Rezende \& Elias $242 *$ \\
\hline C. obliqua Spreng. & av & ma & Machado et al. $116 *$ \\
\hline Xylosma ciliatifolia (Clos) Eichler & av & ma & Torres 1897 (IAC) * \\
\hline \multicolumn{4}{|l|}{ SANTALACEAE - Claudenir S. Caires (UB) - 1/1 } \\
\hline Phoradendron affine (Pohl ex DC.) Engler \& Krause & ee & aa & Machado et al. $133 *$ \\
\hline \multicolumn{4}{|l|}{ SAPINDACEAE - Joana Miloski (CESJ) - 4/4 } \\
\hline Cupania zanthoxyloides Cambess. & av & $\mathrm{ma}$ & Ramos \& Conforti 231 (IAC) * \\
\hline Matayba juglandifolia Radlk. & av & $\mathrm{ca}, \mathrm{bm}$ & Elias et al. $46^{*}$ \\
\hline Paullinia carpopodea Cambess. & $\mathrm{ab}$ & $\mathrm{ca}$ & Rezende et al. $163 * * *$ \\
\hline Serjania multiflora Cambess. & av & ma & Rezende et al. $357 *$ \\
\hline \multicolumn{4}{|l|}{ SAPOTACEAE - 2/2 } \\
\hline Chrysophyllum marginatum (Hook. \& Arn.) Radlk. & $a b$ & $\mathrm{ca}, \mathrm{bm}$ & Rezende et al. $332 *$ \\
\hline Pouteria pachycalyx T.D.Penn & av & $\mathrm{bm}$ & Rezende et al. $58 *$ \\
\hline \multicolumn{4}{|l|}{ SIPARUNACEAE - 1/1 } \\
\hline Siparuna guianensis Aubl. & av & $\mathrm{ca}$ & Machado et al. $106 * * *$ \\
\hline \multicolumn{4}{|c|}{ SOLANACEAE - Eveline Feliciano (CESJ), João Renato Stehmann (BHCB) - 3/13 } \\
\hline Capsicum cf. baccatum L. & er & $\mathrm{ab}$ & Machado et al. $110 *$ \\
\hline C. flexuosum Sendtn. & $\mathrm{ab}$ & bm & Rezende et al. $100 *$ \\
\hline Cestrum cf. amictum Schltdl. & et & $\mathrm{bm}$ & Rezende et al. $161 *$ \\
\hline C. schlechtendahlii G. Don & $a b$ & ma & Mosén $4305(\mathrm{~S}) * *$ \\
\hline C. strigilatum Ruiz \& Pav. & $a b$ & ma & Mosén $664(\mathrm{~S}) * *$ \\
\hline Solanum cf. americanum Mill. & $a b$ & $\mathrm{bm}$ & Rezende et al. $185 * * *$ \\
\hline S. gnaphalocarpum Vell. & $a b$ & $\mathrm{ma}$ & Rezende et al. $85 *$ \\
\hline S. guaraniticum A.St.-Hil. & $\mathrm{ab}$ & $\mathrm{ca}$ & Rezende \& Elias $222 *$ \\
\hline S. palinacanthum Dunal & et & ca, aa & Rezende \& Elias $230 *$ \\
\hline
\end{tabular}

Espécies destacadas em negrito são aquelas citadas na lista de espécies ameaçadas da flora de Minas Gerais (Biodiversitas 2007): O "Criticamente em

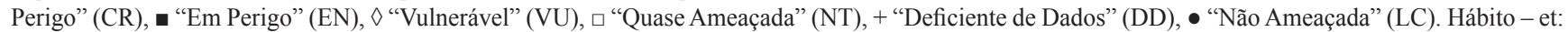
erva terrícola, ee: erva epífita, es: erva saxícola, er: erva rupícola, av: árvore, ab: arbusto, li - liana. Habitat - ca: campo de altitude, ma: interior de mata, bm: borda de mata, aa: área antrópica. Material testemunho: está citado um exemplar para cada espécie. * espécies coletadas apenas no presente estudo ou coletadas recentemente e depositadas nos acervos dos herbários analisados; ** espécies coletadas apenas por Regnell ou colaboradores no século XIX; *** espécies coletadas em ambos os casos.

Species in bold are those cited in the list of threatened species of Minas Gerais flora (Biodiversitas 2007): O "Critically endangered" (CR), "Endangered" $(\mathrm{EN}), \diamond$ "Vulnerable" (VU), $\square$ "Near Threatened" (NT), + "Data Defficient” (DD), • "Least Concern" (LC). Hábito - et: terrestrial herb, ee: epiphyte herb, es: saxicolous herb, er: rupicolous herb, av: tree, ab: shrub, li - liana. Habitat - ca: campo de altitude, ma: forest interior, bm: forest edge, aa: anthropic area. Material testemunho: one specimen is cited for each species. * species collected only on the present study or recently collected and deposited in the analyzed herbaria; ** species collected only by Regnell or collaborators in XIX century; *** species collected on both cases. 
Tabela 1. Continuação...

Table 1. Continued...

\begin{tabular}{|c|c|c|c|}
\hline Famílias/Espécies & Hábito & Habitat & Material testemunho \\
\hline S. paniculatum L. & $\mathrm{ab}$ & $\mathrm{ca}$ & Rezende et al. $327 *$ \\
\hline S. pseudoquina A.St-Hil. & et & $\mathrm{ab}$ & Machado et al. $112 *$ \\
\hline S. sciadostylis (Sendtn.) Bohs & av & $\mathrm{bm}$ & Rezende et al. $131 *$ \\
\hline INDET. & av & $\mathrm{ca}$ & Elias et al. $20 *$ \\
\hline \multicolumn{4}{|l|}{ STYRACACEAE - 1/2 } \\
\hline Styrax leprosus Hook. \& Arn. & $\mathrm{ab}$ & $\mathrm{ma}$ & Monteiro et al. $484 * * *$ \\
\hline S. pohlii A. DC. & av & bm & Rezende et al. $51 *$ \\
\hline \multicolumn{4}{|l|}{ SYMPLOCACEAE - 1/1 } \\
\hline Symplocos platyphylla (Pohl) Benth. + & av & & Regnell I 47 (S) ** \\
\hline \multicolumn{4}{|l|}{ TALINACEAE - 1/1 } \\
\hline Talinum patens (L.) Willd & et & aa & Machado et al. $170 *$ \\
\hline \multicolumn{4}{|l|}{ THYMELAEACEAE $-2 / 2$} \\
\hline Daphnopsis brasiliensis Mart. & $a b$ & $a b$ & Machado et al. $98 *$ \\
\hline D. fasciculata (Meisn.) Nevling & av & $\mathrm{ca}, \mathrm{bm}, \mathrm{ma}$ & Rezende et al. $165^{*}$ \\
\hline \multicolumn{4}{|l|}{ URTICACEAE - 1/2 } \\
\hline Urera baccifera (L.) Gaudich. ex Wedd. & av & $\mathrm{bm}$ & Rezende et al. $108 *$ \\
\hline INDET. & av & bm & Rezende et al. $53 *$ \\
\hline \multicolumn{4}{|c|}{ VERBENACEAE - Fátima R. G. Salimena (CESJ) - 3/6 } \\
\hline Lantana camara L. & $a b$ & $\mathrm{ca}$ & Rezende \& Elias $254 *$ \\
\hline L. fucata Lindl. & $\mathrm{ab}$ & ma, aa & Rezende \& Elias $225 *$ \\
\hline L. lilacina Desf. & $\mathrm{ab}$ & ca, aa & Souza et al. $648 *$ \\
\hline Petrea sp. & $a b$ & & Rezende $224 *$ \\
\hline Verbena alata Moldenke & et & $\mathrm{ca}$ & Regnell $326(\mathrm{NY}) * *$ \\
\hline Verbena sp.1 & et & aa & Machado et al. $154 *$ \\
\hline \multicolumn{4}{|l|}{ VITACEAE - 1/1 } \\
\hline Cissus striata Ruiz \& Pav. & li & $\mathrm{bm}$ & Regnell III 365 (S) ** \\
\hline \multicolumn{4}{|l|}{ VOCHYSIACEAE - 2/3 } \\
\hline Qualea jundiahy Warm. & av & $\mathrm{ca}$ & Machado et al. $115 *$ \\
\hline Vochysia magnifica Warm. & av & $\mathrm{ma}$ & Regnell III $531(\mathrm{~S}) * *$ \\
\hline V. tucanorum Mart. & av & $\mathrm{bm}$ & Valente et al. $558 *$ \\
\hline \multicolumn{4}{|l|}{ XYRIDACEAE $-1 / 3$} \\
\hline Xyris capensis L.A.Nilsson & et & ca & Regnell $1275(\mathrm{MO}) * *$ \\
\hline X. hymenachne Mart. & et & $\mathrm{ca}$ & Regnell $1273(\mathrm{MO}) * *$ \\
\hline Xyris sp. & et, es & $\mathrm{ca}$ & Rezende et al. $113 *$ \\
\hline
\end{tabular}

Espécies destacadas em negrito são aquelas citadas na lista de espécies ameaçadas da flora de Minas Gerais (Biodiversitas 2007): O "Criticamente em

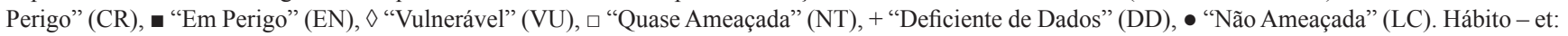
erva terrícola, ee: erva epífita, es: erva saxícola, er: erva rupícola, av: árvore, ab: arbusto, li - liana. Habitat - ca: campo de altitude, ma: interior de mata, bm: borda de mata, aa: área antrópica. Material testemunho: está citado um exemplar para cada espécie. * espécies coletadas apenas no presente estudo ou coletadas recentemente e depositadas nos acervos dos herbários analisados; ** espécies coletadas apenas por Regnell ou colaboradores no século XIX; *** espécies coletadas em ambos os casos.

Species in bold are those cited in the list of threatened species of Minas Gerais flora (Biodiversitas 2007): ○ "Critically endangered" (CR), घ "Endangered" $(\mathrm{EN}), \diamond$ "Vulnerable" (VU), $\square$ "Near Threatened” (NT), + "Data Defficient” (DD), • "Least Concern” (LC). Hábito - et: terrestrial herb, ee: epiphyte herb, es: saxicolous herb, er: rupicolous herb, av: tree, ab: shrub, li - liana. Habitat - ca: campo de altitude, ma: forest interior, bm: forest edge, aa: anthropic area. Material testemunho: one specimen is cited for each species. * species collected only on the present study or recently collected and deposited in the analyzed herbaria; ** species collected only by Regnell or collaborators in XIX century; *** species collected on both cases.

Em termos de habitat, pode ser observado que a maioria das espécies ocorre nas áreas de campo de altitude (ca. 46\%).

As áreas campestres são caracterizadas pela predominância das famílias Poaceae, Cyperaceae, Orchidaceae, Bromeliaceae, Asteraceae, Fabaceae e Rubiaceae, com destaque para as espécies Anthurium minarum (Araceae), Siphocampylus macropodus, $S$. westinianus (Campanulaceae), Doryopteris spp. (Pteridaceae), além de Aechmea distichantha, Vriesea sceptrum (Bromeliaceae), Epidendrum secundum, Bulbophyllum exaltatum (Orchidaceae) e Peperomia oreophila (Piperaceae) nos afloramentos rochosos. No ambiente campestre deve ser mencionada ainda a presença de Melinis minutiflora P. Beauv. (Poaceae), invasora de origem africana.

Nas fisionomias florestais destaca-se a ocorrência das famílias Orchidaceae, Bromeliaceae, Aspleniaceae, Polypodiaceae, Piperaceae, Myrtaceae, Euphorbiaceae, Salicaceae, Fabaceae e Rubiaceae, com destaque para as espécies arborescentes Araucaria angustifolia (Araucariaceae), Dicksonia sellowiana (Dicksoniaceae), Alchornea triplinervia, Sapium glandulosum (Euphorbiaceae), Pimenta pseudocaryophyllus (Myrtaceae) e Rudgea gardenioides (Rubiaceae), além das herbáceas Billbergia distachia, 
Tabela 2. Listagem das áreas utilizadas na análise de similaridade.

Table 2. List of areas used in the similarity analysis.

\begin{tabular}{|c|c|c|c|c|c|}
\hline Sigla & Localidade & $\mathbf{N}$ & Coordenadas & $\begin{array}{l}\text { Altitude } \\
(\mathbf{m})\end{array}$ & Referência \\
\hline SPB & Serra da Pedra Branca - MG & 366 & $21^{\circ} 55^{\prime} \mathrm{S}-46^{\circ} 22^{\prime} \mathrm{W}$ & $1160-1780$ & presente estudo \\
\hline SSJ & Serra de São José - MG & 817 & $21^{\circ} 03^{\prime} \mathrm{S}-44^{\circ} 06^{\prime} \mathrm{W}$ & $900-1430$ & Alves \& Kolbek (2009) \\
\hline PNSC & Parque Nacional da Serra da Canastra - MG & 704 & $20^{\circ} 30^{\prime} \mathrm{S}-46^{\circ} 15^{\prime} \mathrm{W}$ & $800-1400$ & Specieslink (CRIA) \\
\hline SC & Serra do Cipó - MG & 1421 & $19^{\circ} 15^{\prime} \mathrm{S}-43^{\circ} 35^{\prime} \mathrm{W}$ & $800-1300$ & Giulietti et al. (1987) \\
\hline PESB & Parque Estadual da Serra do Brigadeiro - MG & 515 & $20^{\circ} 40^{\prime} \mathrm{S}-42^{\circ} 26^{\prime} \mathrm{W}$ & $1200-1980$ & Leoni \& Tinte (2004) \\
\hline PEI & Parque Estadual de Ibitipoca - MG & 1008 & $21^{\circ} 40^{\prime} \mathrm{S}-43^{\circ} 52^{\prime} \mathrm{W}$ & $1000-1784$ & Forzza et al. (dados não publicados) \\
\hline SN & Serra Negra - MG & 912 & $21^{\circ} 58^{\prime} \mathrm{S}-43^{\circ} 53^{\prime} \mathrm{W}$ & $900-1670$ & Salimena et al. (2013) \\
\hline PNC & Parque Nacional do Caparaó - MG/ES & 414 & $20^{\circ} 20^{\prime} \mathrm{S}-41^{\circ} 45^{\prime} \mathrm{W}$ & $1300-2890$ & Specieslink (CRIA) \\
\hline PNI & Parque Nacional de Itatiaia - RJ/MG & 1804 & $22^{\circ} 30^{\prime} \mathrm{S}-44^{\circ} 35^{\prime} \mathrm{W}$ & $650-2780$ & Specieslink (CRIA) \\
\hline NC & $\begin{array}{l}\text { Núcleo Curucutu } \\
\text { (Parque Estadual da Serra do Mar) - SP }\end{array}$ & 390 & $23^{\circ} 59^{\prime} \mathrm{S}-46^{\circ} 44^{\prime} \mathrm{W}$ & $750-850$ & Garcia \& Pirani (2005) \\
\hline
\end{tabular}

N - Número de espécies de angiospermas utilizadas na análise de similaridade florística. Specieslink: http://www.splink.org.br/. N - Number of angiosperm species used in the floristic similarity analysis. Specieslink: http://splink.org.br/.

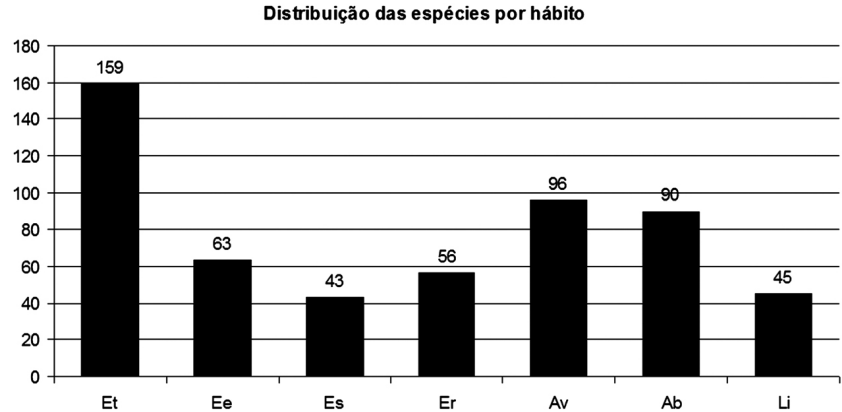

Figura 3. Distribuição das espécies por hábito. Et: erva terrícola; Ee: erva epífita; Es: Erva saxícola, Er: Erva rupícola; Av: árvore; Ab: arbusto; Li: liana.

Figure 3. Distribution of species by habit. Et: terricolous herb; Ee: epiphytic herb; Es: saxicolous herb, Er: rupicolous herb; Av: tree; Ab: shrub; Li: vine.

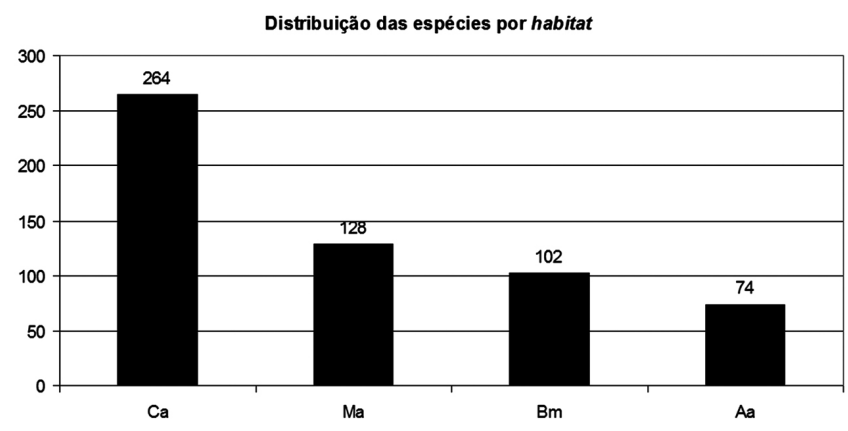

Figura 4. Distribuição das espécies por habitat. Ca: campo de altitude; Ma: interior de mata; Bm: borda de mata; AA: área antropizada.

Figure 4. Distribution of species by habitat. Ca: "campo de altitude"; Ma: interior of forest; Bm: border of forest; AA: anthropic area.

Vriesea sceptrum (Bromeliaceae), Rhipsalis spp. (Cactaceae), Sinningia douglasii (Gesneriaceae), Hymenophyllum polyanthos (Hymenophyllaceae), Pleurothallis rubens (Orchidaceae), Peperomia spp. (Piperaceae), Microgramma squamulosa e Pleopeltis spp. (Polypodiaceae).

As samambaias estão representadas por 59 espécies distribuídas em 27 gêneros e 13 famílias. As três famílias mais representativas foram Polypodiaceae (20 spp.), Dryopteridaceae (10 spp.) e Aspleniaceae (8 spp.), englobando ca. 65\% das espécies de samambaias registradas na área. Os gêneros mais ricos foram
Asplenium (oito spp.), Elaphoglossum (sete spp.), Pecluma e Doryopteris (cinco spp. cada um).

Apenas uma espécie de gimnosperma foi registrada, Araucaria angustifolia (Bertol.) Kuntze (Araucariaceae), nos fragmentos de Floresta Ombrófila Mista.

As angiospermas constituem o grupo de maior representatividade, com 442 espécies pertencentes a 246 gêneros e 86 famílias. As famílias mais ricas foram Orchidaceae (56 spp.), Asteraceae (27 spp.), Fabaceae (26 spp.), Piperaceae (19 spp.), Rubiaceae (17 spp.), Apocynaceae e Bromeliaceae (15 spp. cada uma), Melastomataceae (14 spp.), Solanaceae (13 spp.) e Lamiaceae, Myrtaceae e Poaceae (12 spp. cada uma). Assim, apenas 12 famílias perfazem aproximadamente $53,8 \%$ do total de espécies de angiospermas registradas. Os gêneros mais representativos foram Piper (10 spp.), Peperomia e Tibouchina (nove spp. cada), Mimosa (oito spp.), Solanum (sete spp.), Pleurothallis s.l. e Tillandsia (seis spp. cada), Cyclopogon, Epidendrum, Habenaria, Passiflora, Sinningia (cinco spp. cada um).

Os seguintes táxons não haviam sido registrados para o estado de Minas Gerais, segundo a Lista da Flora do Brasil (Forzza et al. 2012), tendo o conhecimento de sua distribuição geográfica ampliado com a realização do presente estudo: Celtis spinosa Spreng. (Cannabaceae), Croton eichleri Müll. Arg. (Euphorbiaceae), Bunchosia pallescens Skottsb., Heteropterys syringifolia Griseb. (Malpighiaceae) e Myrsine loefgrenii (Mez) Otegui (Primulaceae).

Segundo a mesma obra, as seguintes espécies são endêmicas do estado de Minas Gerais (as espécies provavelmente restritas à região estudada estão destacadas com *): *Campyloneurum vulpinum (Lindm.) Ching (Polypodiaceae), *Pseudibatia suberosa Malme (Apocynaceae), *Eupatoriopsis hoffmanniana Hieron., Hieracium warmingii Baker (Asteraceae), Pitcairnia caldasiana Baker (Bromeliaceae), *Dioscorea caldasensis R.Knuth (Dioscoreaceae), *Eriocaulon regnellii Moldenke (Eriocaulaceae), Dalechampia regnellii Müll. Arg. (Euphorbiaceae), Microlepis mosenii Cogn. (Melastomataceae), *Prosthechea regnelliana (Hoehne \& Schltr.) W.E.Higgins (Orchidaceae), Phyllanthus dictyospermus Müll. Arg. (Phyllanthaceae), Eragrostis apiculata Döll (Poaceae).

Dentre as plantas vasculares registradas na SPB, 13 são citadas na lista de espécies ameaçadas de Minas Gerais (Biodiversitas 2007), pertencentes a 10 famílias, nas categorias "Criticamente em Perigo" (CR) (uma sp.); "Em Perigo" (EN) (uma sp.), "Vulnerável” (VU) (cinco spp.), "Quase Ameaçada" (NT) (uma sp.), além de cinco espécies na categoria de "Deficiente de Dados" (DD) em que as 
informações disponíveis não são suficientes para uma caracterização mais precisa, embora provavelmente estejam ameaçadas. Ainda, três outras espécies são citadas como "Não Ameaçadas" (LC), pois tiveram seu status revisado em relação à lista apresentada por Mendonça \& Lins (2000) (Tabela 1). Apenas Alstroemeria variegata M.C.Assis está citada na lista de espécies ameaçadas do Brasil como Deficiente de Dados (Brasil 2008).

O levantamento nos acervos dos herbários supracitados resultou em 127 espécies coletadas por Regnell e colaboradores na SPB. Apenas 29 espécies foram recoletadas no presente estudo ou em coletas recentes depositadas nas coleções dos herbários analisados. Assim, dentre as espécies citadas na Tabela 2, 375 foram adicionadas àquelas já coletadas na região, sendo mais de $90 \%$ proveniente de coletas realizadas especificamente para o presente estudo.

A análise de similaridade resultou no dendrograma apresentado na Figura 5 em que, de modo geral, podem ser observados dois grupos principais. O primeiro formado (A) pelas áreas de campo rupestre no Domínio do Cerrado: Serra de São José (SSJ), Serra do Cipó (SC) e Parque Nacional da Serra da Canastra (PNSC). O segundo (B) com áreas de campo rupestre (Parque Estadual de Ibitipoca (PEI) e Serra Negra (SN)) e campos de altitude (Parque Nacional do Itatiaia (PNI), Parque Nacional do Caparaó (PNC), Parque Estadual da Serra do Brigadeiro (PESB)) localizados na Serra da Mantiqueira, no Domínio Atlântico e separado neste ramo o Núcleo Curucutu (NC), em São Paulo. A SPB (*) ficou em um ramo isolado, com baixa similaridade em relação aos dois grandes grupos formados (ca. 0,05). O coeficiente de correlação cofenético foi de 0,8597 , mostrando que o método de agrupamento aplicado causou distorção reduzida entre a matriz e o dendrograma obtido.

\section{Discussão}

\section{Flora}

A maior predominância das espécies de hábito herbáceo e arbustivo, ocorrendo no campo de altitude, em detrimento das espécies arbóreas (seja em ambiente campestre ou nas fisionomias florestais), segue o padrão típico observado em ambientes montanos similares, nos quais a vegetação é formada por mosaico constituído por arbustos e pequenas árvores, muitas vezes atrofiadas, situados em uma matriz com várias espécies de Poaceae, Cyperaceae, Orchidaceae, Bromeliaceae, Xyridaceae e samambaias (Safford 1999a).

A composição florística é discutida a seguir para os grupos de samambaias e angiospermas, abordando as famílias de maior destaque nas fisionomias campestres e florestais da Serra da Pedra Branca.

A Floresta Atlântica é considerada um dos grandes centros de diversidade e endemismos de samambaias da região Neotropical, sendo as regiões montanhosas uma das áreas mais ricas (Tryon 1972). Segundo Moran (1995) as montanhas influenciam na distribuição e diversidade das samambaias impedindo a migração e promovendo assim elevada riqueza e endemismo. Na SPB, três famílias se destacaram em relação à riqueza: Polypodiaceae, Dryopteridaceae e Aspleniaceae. Segundo Smith et al. (2006) e Haufler (2007), Polypodiaceae, a mais rica dentre as samambaias da Serra da Pedra Branca, é considerada uma das famílias mais representativas deste grupo, se refletindo também nos campos de altitude (Safford 1999a, Ribeiro et al. 2007). Esse padrão também foi observado em campos rupestres e florestas montanas em estudos realizados por Figueiredo
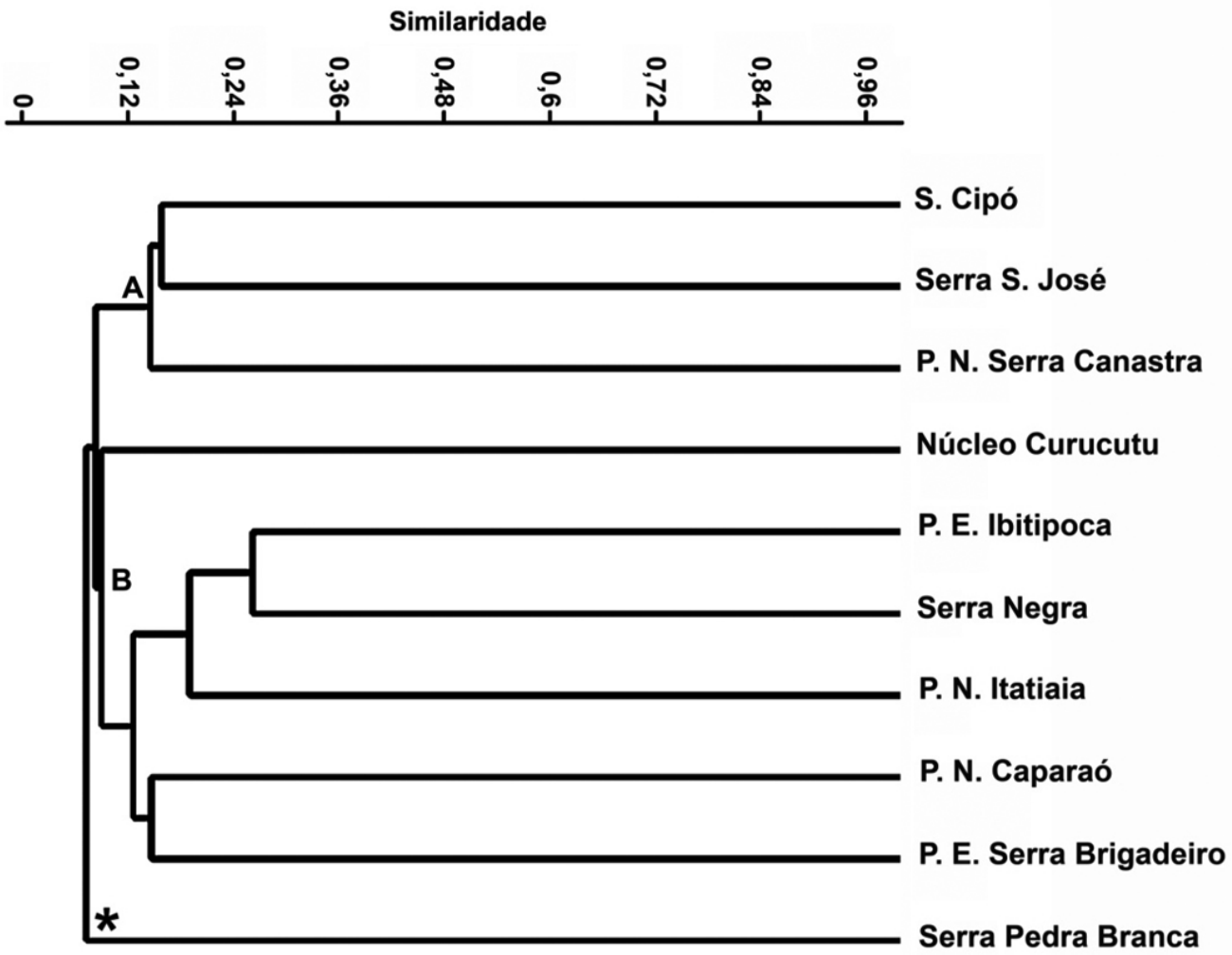

Figura 5. Dendrograma resultante da análise de similaridade, empregando o coeficiente de Jaccard, entre 10 áreas com predominância de vegetação campestre na Região Sudeste do Brasil. Coeficiente de correlação cofenética 0,8597. * ramo da Serra da Pedra Branca.

Figure 5. Dendrogram resulting from similarity analysis, using Jaccard coefficient, between 10 areas with predominance of field vegetation in Southeastern Region of Brasil. Cophenetic coefficient 0.8597. * Serra da Pedra Branca branch. 
\& Salino (2005) na região metropolitana de Belo Horizonte, por Melo \& Salino (2007) em fragmentos florestais da APA Fernão Dias no Sul de Minas Gerais e por Souza et al. (2012) na Serra Negra e Salino et al. (dados não publicados) no Parque Estadual de Ibitipoca, ambos na Zona da Mata do estado de Minas Gerais.

As famílias mais ricas de angiospermas na área estudada são frequentemente citadas entre as mais representativas em áreas predominantemente campestres em Minas Gerais, seja em campos de altitude ou campos rupestres, embora em ordem variada (Giulietti et al. 1987, Pirani et al. 2003, Leoni \& Tinte 2004, Alves \& Kolbek 2009, Salimena et al. 2013, Forzza et al. dados não publicados).

As três principais famílias em número de espécies na SPB (Orchidaceae, Asteraceae e Fabaceae) são também as mais ricas de forma global (Judd et al. 2009), na flora do Brasil (Forzza et al. 2010), e, em menor escala, no Domínio Atlântico (Stehmann et al. 2009) embora em ordem diversa nas três escalas.

Especificamente para o Domínio Atlântico, Orchidaceae é a família mais rica, figurando frequentemente como a mais representativa em estudos realizados em área com predominância de campo de altitude ou campo rupestre, como no PESB (Leoni \& Tinte 2004, Caiafa \& Silva 2005), PEI (Menini Neto et al. 2007) e Serra Negra (Abreu et al. 2011).

Asteraceae e Rubiaceae estão entre as famílias com maior riqueza em inventários florísticos de campos rupestres como apresentado no levantamento florístico realizado por Alves \& Kolbek (2009). Ribeiro et al. (2007) destacam que essas duas famílias estão entre as mais dominantes nos campos de altitude do PNI, padrão este encontrado nas áreas campestres em geral. De acordo com Gentry (1995), a família Rubiaceae torna-se mais rica em altitudes entre 1500 a $2000 \mathrm{~m}$, sendo considerada a segunda família com maior riqueza nessa classe altitudinal. Nas florestas brasileiras, presentes em elevadas altitudes, esse padrão florístico também é observado, sendo considerada uma das mais representativas (Oliveira-Filho \& Fontes 2000, Pereira et al. 2006).

Fabaceae também foi significativa na área de estudo, assim como apresentado por Mourão \& Stehmann (2007) e Viana \& Lombardi (2007), para os campos rupestres sobre canga na região do Quadrilátero Ferrífero de Minas Gerais e por Alves \& Kolbek (2009), embora, por outro lado, para uma área de campo de altitude essa representatividade não tenha sido encontrada por Caiafa \& Silva (2005). Ainda, a presença de poucas espécies de Fabaceae nas fisionomias florestais da SPB, acima de $1500 \mathrm{~m}$ de altitude, reflete o padrão de riqueza conhecido para a família no qual, em altitudes elevadas, ocorre um decréscimo de sua riqueza (Gentry 1995 , Oliveira-Filho \& Fontes 2000, França \& Stehmann 2004).

Piperaceae foi objeto de estudo no município de Caldas por Salomon Henschen, que descreveu diversas novas espécies durante o século XIX (Henschen 1873). Representa a quarta família mais rica e seus gêneros, Piper e Peperomia, são os dois mais representativos na SPB. No Brasil, Piperaceae apresenta grande concentração de espécies na Floresta Atlântica, distribuída principalmente nestes dois gêneros (Yuncker 1972, 1973, 1974), justificando a representatividade de ambos na SPB. De modo semelhante, a família também se mostrou representativa na composição das floras do Parque Nacional do Itatiaia (Monteiro \& Guimarães 2008, 2009), da Serra de São José (Alves \& Kolbek 2009) e da Serra Negra (Salimena et al. 2013).

Peperomia também foi um dos gêneros mais representativos tanto na Serra Negra (Salimena et al. 2013), quanto no Parque Estadual de Ibitipoca (Forzza et al., dados não publicados). O gênero também figura como o mais rico entre as espécies epifíticas da SPB, corroborando o estudo realizado por Menini Neto et al. (2009) e tal riqueza deve-se nas três áreas supracitadas (SPB, SN e PEI) aos fragmentos de florestas montanas entremeados às áreas campestres, fornecendo ambiente propício ao seu estabelecimento. $\mathrm{O}$ hábito epifítico de muitas espécies de Piperaceae também auxilia na melhor adaptação a diferentes ambientes (Smith et al. 2008).

Outra família com representatividade destacada, tanto em número de espécies quanto em número de indivíduos na SPB foi Bromeliaceae, embora em Minas Gerais ocorra nítida diminuição da diversidade no sentido leste para oeste do estado, com a maior concentração de riqueza no sul da Cadeia do Espinhaço e no sudeste do estado (Versieux \& Wendt 2007). Leoni \& Tinte (2004), Salimena et al. (2013) e Forzza et al. (dados não publicados) também destacam a importância da família Bromeliaceae na composição florística de áreas predominantemente campestres na Serra da Mantiqueira.

Bromeliaceae foi a única família estudada em detalhe até o momento na SPB e Machado \& Menini Neto (2010) apontaram que algumas espécies formam extensas populações nas altitudes mais elevadas da área, acima de 1700m: Aechmea distichantha Lem., Vriesea sceptrum Mez e Wittrockia cyathiformis (Vell.) Leme. A alta disponibilidade de umidade favorecida pelas matas nebulares, bem representadas nessa classe altitudinal na área de estudo, pode ter favorecido a adaptação dessas espécies em elevadas altitudes (Webster 1995). Tillandsia foi um dos gêneros mais ricos e o segundo mais representativo entre as espécies epifíticas da SPB. A elevada riqueza deste gênero foi destacada por Versieux \& Wendt (2007) em estudo realizado sobre a diversidade de Bromeliaceae para o estado de Minas Gerais, por Martinelli et al. (2008) no Domínio Atlântico no Brasil e por Menini Neto et al. (2009) em diversos fragmentos florestais no Sudeste de Minas Gerais.

\section{Relações florísticas}

A análise de similaridade realizada neste estudo demonstra a peculiaridade da composição da flora da Serra da Pedra Branca, embora fisionomicamente sua vegetação predominantemente campestre guarde semelhanças com as demais áreas usadas na comparação. Esta singularidade da flora reforça ainda a importância dada por Drummond et al. (2005) que indicaram a necessidade de inventários florísticos na região reconhecendo-a como potencialmente importante para a conservação da flora de Minas Gerais, fato confirmado com os resultados ora apresentados.

Aparentemente há reduzida influência do domínio fitogeográfico ou altitude, nas relações florísticas entre a SPB e as demais áreas utilizadas na análise de similaridade, devido ao completo isolamento da área estudada em relação às demais. Possivelmente, esta relação observada é devida, pelo menos em parte, às respectivas bacias hidrográficas em que as áreas se encontram, que podem atuar como barreiras geográficas à dispersão das espécies, aumentando a heterogeneidade entre essas áreas campestres.

A SPB faz parte da Bacia do Rio Paraná (Instituto... 2000), enquanto as demais áreas do Domínio Atlântico usadas na comparação estão incluídas na Bacia do Atlântico Leste (com exceção do Núcleo Curucutu, que faz parte da Bacia do Atlântico Sudeste). As três áreas pertencentes ao Domínio do Cerrado (P.N. da Serra da Canastra, Serra do Cipó e Serra de São José) fazem parte de bacias distintas, estando predominantemente localizadas na Bacia do Rio São Francisco embora, PNSC e SSJ, estejam em uma região de transição com a Bacia do Rio Paraná e a SC, esteja na transição com a Bacia do Atlântico Leste.

Em uma escala mais ampla, a análise comparativa da flora de diversas áreas de altitude das Américas do Sul e Central feita por Safford (1999a, b, 2007) mostra maior relação de gêneros e espécies entre campos de altitude e áreas andinas do que com áreas próximas geograficamente no leste e região central do Brasil, como aquelas 
de cerrado e restinga (Safford 2007). Variações climáticas ocorridas no final do Terciário e Quaternário permitiram que diversas espécies temperadas e tropicais andinas migrassem em direção aos campos de altitude e, atualmente, análises amplas dos dados climáticos evidenciam elevadas congruências entre essas áreas e os Andes (Safford 1999a, b). As floras atuais dos Andes e campos de altitude apresentam elevada afinidade biogeográfica e podem ser consideradas oriundas de uma mistura formada principalmente por elementos fitogeográficos tropicais, temperados e cosmopolitas (Safford 2007).

Os gêneros listados por Safford (1999a, 2007) para os Andes, e compartilhados com a Serra da Pedra Branca, são os seguintes: Andropogon, Begonia, Bulbostylis, Cassia, Cissus, Cleome, Croton, Cyperus, Doryopteris, Elaphoglossum, Eriocaulon, Eugenia, Genlisea, Habenaria, Hymenophyllum, Hyptis, Lantana, Maytenus, Mikania, Mimosa, Ocotea, Paspalum, Peperomia, Phyllanthus, Phytolacca, Pleopeltis, Polystachya, Rapanea, Rhipsalis, Setaria, Symplocos, Vitex, Xyris (Tropical, amplamente distribuídos); Araucaria, Dicksonia, Fuchsia, Rumohra, Sisyrinchium (Austral-Antártico, temperado do Hemisfério Sul); Carex, Eriocaulon, Hieracium, Juncus, Prunus, Rubus, Senecio, Thelypteris (Cosmopolita); Anagallis, Asplenium, Bidens, Blechnum, Borreria, Botrychium, Cerastium, Dioscorea, Eragrostis, Eryngium, Galium, Huperzia, Hydrocotyle, Oxalis, Panicum, Polygala, Polypodium, Polystichum, Solanum, Utricularia (Temperado, amplamente distribuídos).

Pelo menos $11 \%$ das espécies vasculares analisadas no estudo realizado por Safford (2007) são compartilhadas entre os campos de altitude e os Andes, sendo o número de criptógamas compartilhadas bastante elevado, evidenciando uma forte conexão florística entre essas áreas. Dentre as espécies utilizadas nessas análises, são compartilhadas com a Serra da Pedra Branca: as samambaias Asplenium auritum, Dicksonia sellowiana, Elaphoglossum gayanum, Hymenophyllum polyanthos e Rumohra adiantiformis e as angiospermas Cissus striata e Peperomia galioides.

Áreas antes contínuas e climaticamente similares, como os Andes e os campos de altitude, foram separadas em distância e altitude ao longo dos períodos geológicos (Safford 1999a), porém, a análise de diversos aspectos climáticos mostra que os campos de altitude podem ser considerados uma variação dos páramos tropicais andinos com uma grande sazonalidade (Safford 1999b), além de serem consideradas ilhas de clima temperado acima da Floresta Tropical Atlântica (Safford 2007).

\section{Conservação}

Diversos autores vêm ressaltando a riqueza, endemismos e fragilidades dos ambientes campestres ou rochosos de altitude evidenciando assim, a necessidade de priorizar a proteção e conservação desses ambientes (Meirelles et al. 1999, Safford 1999a, Giulietti et al. 2000, Porembski 2007, Ribeiro et al. 2007, Viana \& Lombardi 2007, Martinelli 2007). Fica patente a importância de proteção da SPB que é a localidade-típica de várias espécies, em sua maioria coletada por Regnell no século XIX, sendo muitas delas endêmicas da região ou raramente coletadas em outras localidades. Octomeria leptophylla Barb. Rodr. (Orchidaceae) é um exemplo cuja localidade-típica é a SPB, tendo sido considerada extinta por Biodiversitas (2007) e recentemente redescoberta (Menini Neto \& Docha Neto 2009), embora não na SPB, mas em duas serras de municípios próximos, Andradas e Poços de Caldas, não tendo sido observada na área durante o presente estudo.

A presença de espécies ameaçadas de extinção e endêmicas associada à singularidade biótica da área e ao elevado ritmo de destruição ao qual o ambiente foi e está sendo submetido devido à intensa visitação e elevada atividade minerária que ocorre na Serra da Pedra Branca evidencia a urgente e necessária conservação de seus afloramentos rochosos. O fato de apenas 29 das espécies anteriormente registradas por Regnell terem sido recoletadas e 375 outras serem registradas pela primeira vez reforça a relevância deste argumento e a importância do presente estudo que confirma o potencial da região sugerido por Drummond et al. (2005). O incentivo à pesquisa é essencial, devido ao incipiente conhecimento científico da região. Para conservar a biota local é necessário maior comprometimento das autoridades e maior fiscalização dos órgãos ambientais, uma vez que a região está inserida em uma Área de Proteção Ambiental que por definição é uma categoria de unidade de conservação com ocupação permitida, não apresentando assim, elevado poder de conservação (Menini Neto \& Docha Neto 2009).

\section{Agradecimentos}

Agradecemos a CAPES e FAPEMIG pelas bolsas concedidas aos dois primeiros autores, ao Programa de Pós-Graduação em Ecologia da Universidade Federal de Juiz de Fora. Aos especialistas das famílias e a todos que auxiliaram nas identificações das espécies. Ao Márcio Malafaia Filho pela confecção do mapa apresentado na Figura 2, à Transportadora Menezes de Poços de Caldas pelo apoio logístico e ao botânico Filipe Soares de Souza pelo auxílio em diversas etapas do trabalho. Ao Tiago Henrique Ramos pela revisão do abstract.

\section{Referências Bibliográficas}

ABREU, N.L., MENINI NETO, L. \& KONNO, T.U.P. 2011. Orchidaceae das Serras Negra e do Funil, Rio Preto, Minas Gerais, e similaridade florística entre formações campestres e florestais do Brasil. Acta. Bot. Bras. 25(1):58-70.

ALVES, R.J.V. \& KOLBEK, J. 2009. Summit vascular flora of Serra de São José, Minas Gerais, Brasil. Check List 5(1):35-73.

AGÊNCIA NACIONAL DE ÁGUAS - ANA. 2005. http://hidroweb.ana.gov. br (último acesso em 04/03/2009).

ANGIOSPERM PHYLOGENY GROUP III - APG III. 2009. An update of the Angiosperm Phylogeny Group classification for the orders and families of flowering plants: APG III. Bot. J. Linn. Soc. 161:105-121.

BENITES, V.M., CAIAFA, A.N., MENDONÇA, E.S, SCHAEFER, C.E. \& KER, J.C. 2003. Solos e vegetação nos complexos rupestres de altitude da Mantiqueira e Espinhaço. Floresta e Ambiente 10(1):76-85.

BIODIVERSITAS. 2007. Revisão das listas das espécies da flora e da fauna ameaçadas de extinção do estado de Minas Gerais. Fundação Biodiversitas, Belo Horizonte, p.1-69. (Relatório final, v.2).

BRADE, A.C. 1956. A flora do Parque Nacional do Itatiaia. Boletim do Parque Nacional do Itatiaia 5:1-114.

BRASIL. Ministério do Meio Ambiente. 2000. Avaliação e ações prioritárias para a conservação da biodiversidade da Mata Atlântica e Campos Sulinos. MMA/SBF, Brasília, 40p.

BRASIL. Ministério do Meio Ambiente. 2008. Lista Nacional das Espécies da Flora Brasileira Ameaçada de Extinção. http://www.mma.gov.br/ estruturas/179/ arquivos/179 05122008033615.pdf (último acesso em $11 / 01 / 2010)$.

BRUMMITT, R.K. \& POWELL, C.E. 1992. Authors of plants names. Kew, Royal Botanic Gardens, p.1-732.

CAIAFA, A.N. \& SILVA, A.F. 2007. Structural analysis of the vegetation on a highland granitic rock outcrop in Southeast Brazil. Rev. Bras. Bot. 30(4):657-664.

CAIAFA, A.N. \& SILVA, A.F. 2005. Composição florística e espectro biológico de um campo de altitude no Parque Estadual da Serra do Brigadeiro, Minas Gerais-Brasil. Rodriguésia 56(87):163-173.

CÂMARA, I.G. 2003. Brief history of conservation in the Atlantic Forest. In The Atlantic Forest of South America: biodiversity status, threats, 
and outlook (C. Galindo-leal \& I. G. Câmara, eds.). Center for Applied Biodiversity Science and Island Press, Washington, p.31-42.

CONFORTI, T.B., RAMOS, E., ADAMI, S.F., ROSAS, P.F.C., BATISTA FILHO, J.J., CAPONI. H.L. \& PARDALIS, A.A. 2007. Zoneamento da APA "Santuário Ecológico da Pedra Branca" Unidade de Conservação Municipal, Caldas, 116p.

DEAN, W. 1996. A ferro e fogo: a história e a devastação da Mata Atlântica brasileira. Companhia das Letras, São Paulo, 484p.

DRUMMOND, G.M., MARTINS, C.S., MACHADO, A.B.M., SEBAIO, F.A. \& ANTONINI, Y. 2005. Biodiversidade em Minas Gerais, um atlas para sua conservação. 2. ed. Fundação Biodiversitas, Belo Horizonte, 222p.

FERRI, M.G. 1980. Vegetação Brasileira. Universidade de São Paulo, São Paulo, $157 \mathrm{p}$.

FIGUEIREDO, J.B. \& SALINO, A. 2005. Samambaias de quatro Reservas Particulares do Patrimônio Natural ao sul da região metropolitana de Belo Horizonte, Minas Gerais, Brasil. Lundiana 6(2):83-94.

FORZZA, R.C., BAUMGRATZ, J.F.A., BICUDO, C.E.M., CANHOS, D.A.L., CARVALHO JUNIOR, A.A., COSTA. A., COSTA, D.P., HOPKINS, M., LEITMAN, P.M., LOHMANN, L.G., LUGHADHA, E.N., MAIA, L.C., MARTINELLI, G., MENEZES, M., MORIM, M.P., COELHO, M.A.N., PEIXOTO, A.L., PIRANI, J.R., PRADO, J., QUEIROZ, L.P., SOUZA, S., SOUZA, V.C., STEHMANN, J.R., SYLVESTRE, L.S., WALTER, B.M.T. \& ZAPPI, D. 2010. Introdução. In Catálogo de plantas e fungos do Brasil (R.C. Forzza, J.F.A. Baumgratz, C.E.M. Bicudo Junior, A.A. Carvalho, A. Costa, D.P. Costa, M. Hopkins, P.M. Leitman, L.G. Lohmann, L.C. Maia, G. Martinelli, M. Menezes, M.P. Morim, M.A.N. Coelho, A.L. Peixoto, J.R. Pirani, J. Prado, L.P. Queiroz, V.C. Souza, J.R. Stehmann, L.S. Sylvestre, B.M.T. Walter \& D. Zappi, eds.). Jardim Botânico do Rio de Janeiro, Rio de Janeiro, v.1, p.19-42.

FORZZA, R.C., STEHMANN, J.R., COELHO, M.A.N., FILARDI, F.L.R., COSTA. A., CARVALHO JUNIOR, A.A., PEIXOTO, A.L., WALTER, B.M.T., BICUDO, C.E.M., MOURA, C.W.N., ZAPPI, D., COSTA, D.P., LLERAS, E., MARTINELLI, G., LIMA, H.C., PRADO, J., BAUMGRATZ, J.F.A., PIRANI, J.R., SYLVESTRE, L.S., MAIA, L.C., LOHMANN, L.G., QUEIROZ, L.P., ALVES, M.V.S., SILVEIRA, M., MAMEDE, M.C.H., BASTOS, M.N.C., MORIM, M.P., BARBOSA, M.R., MENEZES, M., HOPKINS, M., EVANGELISTA, P.H.L., GOLDENBERG, R., SECCO, R., RODRIGUES, R.S., CAVALCANTI, T. \& SOUZA, V.C. 2012. Lista de Espécies da Flora do Brasil. http:// floradobrasil.jbrj.gov.br/2012 (último acesso em 24/06/2012).

FRANÇA, G.S. \& STEHMANN, J.R. 2004. Composição florística e estrutura do componente arbóreo de uma floresta altimontana no município de Camanducaia, Minas Gerais, Brasil. Rev. Bras. Bot. 27(1):19-30.

GARCIA, R.J.F. \& PIRANI, J.R. 2005. Análise florística, ecológica e fitoecológica do Núcleo Curucutu, Parque Estadual da Serra do Mar (São Paulo, SP), com ênfase nos campos junto à crista da Serra do Mar. Hoehnea 32(1):1-48.

GATTO, L.C.S., RAMOS, V.L.S., NUNES, B.T.A., MAMEDE, L., GÓES, M.H.B, MAURO, C.A., ALVARENGA, S.M., FRANCO, E.M.S., QUIRICO, A.F. \& NEVES, L.B. 1983. Geomorfologia. In Projeto RADAMBRASIL - Levantamento dos Recursos Naturais - Folhas Sf. 23/24 Rio de Janeiro/Vitória (Brasil. Ministério das Minas e Energia, ed.). MME/SG/Projeto RADAMBRASIL, Rio de Janeiro, v.32, p.305-384.

GENTRY, A.H. 1995. Patterns of diversity and floristic composition in neotropical montane forests. In Biodiversity and conservation of Neotropical montane forest (S.P. Churchill, H. Balslev, E. Forero \& J.L. Luteyn, eds.). New York Botanical Garden, New York, p.103-126.

GIULIETTI, A.M., MENEZES, N.L., PIRANI, J.R., MEGURO, M. \& WANDERLEY, M.G.L. 1987. Flora da Serra do Cipó, Minas Gerais: caracterização e lista das espécies. Bol. Bot. Univ. São Paulo 9:1-151.

GIULIETTI, A.M., HARLEY, R.M., QUEIROZ, L.P., WANDERLEY, M.G.L. \& PIRANI, J.R. 2000. Caracterização e endemismos nos campos rupestres da Cadeia do Espinhaço. In Tópicos atuais em botânica (T.B. Cavalcanti \& B.M.T. Walter, eds.). Embrapa Recursos Genéticos, Brasília, p.311-318.

HAMMER, Ø., HARPER, D.A.T. \& RYAN, P.D. 2001. PAST: paleontological Statistics software package for education and data analysis. Paleontol. Elec. 4(1):1-9.
HAUFLER, C.H. 2007. Genetics, phylogenetics, and biogeography: Considering how shifting paradigms and continents influence fern diversity. Brittonia 59(2):108-114.

HENSCHEN, S. 1873. Études sur le genre Peperomia, comprenant les espéces de Caldas, Brésil. Nova Acta Regiae Soc. Sci. Upsal. 8:1-53.

HIROTA, M.M. 2003. Monitoring the Brazilian Atlantic Forest cover. In The Atlantic Forest of South America (C. Galindo-Leal \& I.G. Câmara, eds.). Center for Applied Biodiversity Science and Island Press, Washington, p.60-65.

INSTITUTO BRASILEIRO DE GEOGRAFIA E ESTATÍSTICA - IBGE. 2000. Saneamento básico segundo bacia hidrográfica. In Atlas nacional do Brasil (Instituto Brasileiro de Geografia e Estatística. 3. ed. IBGE, Rio de Janeiro, p.99.

INSTITUTO BRASILEIRO DE GEOGRAFIA E ESTATÍSTICA - IBGE. 2007. Cidades. http://www.ibge.gov.br/cidadesat/topwindow.htm?1 (último acesso em 04//03/2009).

INSTITUTO NACIONAL DE METEOROLOGIA - INMET. Seção de Armazenamento de Dados Meteorológicos. 2012. http://www.inmet. gov.br/html/central_servicos/combo_produtos.html. (último acesso em 24/06/2012).

JUDD, W.S.; CAMPBELL, C.S.; KELLOG, E.A.; STEVENS, P.F. \& DONOUGHUE, M.J. 2009. Sistemática Vegetal: Um Enfoque Filogenético. 3. ed. Artmed Editora, Porto Alegre, 632p.

LEINZ, V. \& AMARAL, S.E. 1989. Geologia geral. Companhia Editora Nacional, São Paulo, 487p.

LEONI, L.S. 1997. Catálogo preliminar das fanerógamas ocorrentes no Parque Nacional do Caparaó - MG. Pabstia 8(2):1-28.

LEONI, L.S. \& TINTE, V.A. 2004. Flora do Parque Estadual do Brigadeiro: caracterização da vegetação e lista preliminar das espécies. Universidade Estadual de Minas Gerais, Carangola, 91p.

LINDBERG, B.S. 2011. Anders Fredrik Regnell: Läkare, botanist och donator. Acta Univ. U., Uppsala, 244p.

LUTZ, B. 1926. The Flora of the Serra da Bocaina. Proc. Am. Phil. Soc. 65(5):27-43.

MACHADO, T.M. \& MENINI NETO, L. 2010. Bromeliaceae de um campo de altitude no sul de Minas Gerais (Brasil). Fontqueria 56(13):109-124.

MARTINELLI, G. 2007. Mountain biodiversity in Brazil. Rev. Bras. Bot. 30(4):587-597.

MARTINELLI, G., VIEIRA, C.M., GONZALEZ, M., LEITMAN, P., PIRATININGA, A., COSTA, A.F. \& FORZZA, R.F. 2008. Bromeliaceae da Mata Atlântica brasileira: lista de espécies, distribuição e conservação. Rodriguésia 59(1):209-258.

MEIRELLES, S.T., PIVELLO, V.R. \& JOLY, C.A. 1999. The vegetation of granite rock outcrops in Rio de Janeiro, Brazil, and the need for its protection. Environ. Conserv. 26(1):10-20.

MELO, L.C.N. \& SALINO, A. 2007. Samambaias em fragmentos florestais da Apa Fernão Dias, Minas Gerais, Brasil. Rodriguésia 58(1):207-220.

MENDONÇA, M.P. \& LINS, L.V. 2000. Lista vermelha das espécies ameaçadas de extinção da flora de Minas Gerais. Fundação Biodiversitas, Fundação Zoo-Botânica, Belo Horizonte, 157p.

MENINI NETO, L., ALVES, R.J.V., BARROS, F. \& FORZZA, R.C. 2007. Orchidaceae do Parque Estadual de Ibitipoca, MG, Brasil. Acta Bot. Bras. 21(3):687-696.

MENINI NETO, L. \& DOCHA NETO, A. 2009. Redescoberta e tipificação de Octomeria leptophylla Barb. Rodr. (Orchidaceae), micro-orquídea endêmica de Minas Gerais, Brasil. Rodriguésia 60(2):461-465.

MENINI NETO, L., FORZZA, R.C. \& ZAPPI, D. 2009. Angiosperm epiphytes as conservation indicators in forest fragments: A case study from southeastern Minas Gerais, Brazil. Biodivers. Conserv. 18:3785-3807.

MITTERMEIER, R.A., GIL, P.R, HOFFMAN, M., PILGRIM, J., BROOKS, T., MITTERMEIER, C.G., LAMOREUX, J. \& FONSECA, G.A.B. 2005. Hotspots revisited: Earth's biologically richest and most endangered terrestrial ecoregions. Conservation International, Washington, 392p. 
MONTEIRO, D. \& GUIMARÃES, E.F. 2008. Flora do Parque Nacional do Itatiaia - Brasil: Peperomia (Piperaceae). Rodriguésia 59(1):161-195.

MONTEIRO, D. \& GUIMARÃES, E.F. 2009. Flora do Parque Nacional do Itatiaia - Brasil: Manekia e Piper (Piperaceae). Rodriguésia 60(4):9991024.

MORAN, R. 1995. The importance of mountains to pteridophytes with emphasis on neotropical montane forests. In Biodiversity and Conservation of Neotropical Montane Forests (S.P. Churchill, H. Balslev, E. Forero, \& J.L. Luteyn, eds.). The New York Botanical Garden, New York, p.359-366.

MOURÃO, A. \& STEHMANN, J.R. 2007. Levantamento da flora do campo rupestre sobre canga hematítica couraçada remanescente na Mina do Brucutu, Barão de Cocais, Minas Gerais, Brasil. Rodriguésia 58(4):775-786.

OLIVEIRA-FILHO, A.T. \& FONTES, M.A.L. 2000. Patterns of floristic differentiation among Atlantic Forests in Southeastern Brazil and the influence of climate. Biotropica 32(4):793-810.

PELL, M.C., FINLAYSON, B.L. \& MCMHON, T.A. 2007. Updated world map of the Köppen-Geiger climate classification. Hydrol. Earth Syst. Sci. 11:1633-1644.

PEREIRA, I.M., OLIVEIRA-FILHO, A.T., BOTELHO, S.A., CARVALHO, W.A.C., FONTES, M.A.L., SCHIAVINI, I. \& SILVA, A.F. 2006. Composição florística do compartimento arbóreo de cinco remanescentes florestais do Maciço do Itatiaia, Minas Gerais e Rio de Janeiro. Rodriguésia 57(1):103-126.

PIRANI, J.R., MELLO-SILVA, R. \& GIULIETTI, A.M. 2003. Flora de Grão-Mogol, Minas Gerais, Brasil. Bol. Bot. Univ. São Paulo 21:1-24.

POREMBSKI, S. 2007. Tropical inselbergs: habitat types, adaptive strategies and diversity patterns. Rev. Bras. Bot. 30(4):579-586.

RIBEIRO, K.T., MEDINA, B.M.O. \& SCARANO, F.R. 2007. Species composition and biogeographic relations of the rock outcrop flora on the high plateau of Itatiaia, SE-Brazil. Rev. Bras. Bot. 30(4):623-639.

RIBEIRO, M.C., METZGER, J.P., MARTENSEN, A.C., PONZONI, F.J. \& HIROTA, M.M. 2009. The Brazilian Atlantic Forest: How much is left, and how is the remaining forest distributed? Implications for conservation. Biol. Conserv. 142:1144-1156.

SAFFORD, H.D. 1999a. Brazilian Páramos I. An introduction to the physical environment and vegetation of the campos de altitude. J. Biogeogr. 26: 693-712.

SAFFORD, H.D. 1999b. Brazilian Páramos II. Macro- and mesoclimate of the campos de altitude and affinities with mountain climates of the tropical Andes and Costa Rica. J. Biogeogr. 26:713-737.

SAFFORD, H.D. 2007. Brazilian Páramos IV. Phytogeography of the campos de altitude. J. Biogeogr. 34: 1701-1722.
SALIMENA, F.R.G., MATOZINHOS, C.N., ABREU, N.L., RIBEIRO, J.H.C. \& MENINI NETO, L. 2013. Flora fanerogâmica da Serra Negra, Minas Gerais, Brasil. Rodriguésia 64(2):311-320.

SMITH, A.R., PRYER, K.M., SCHUETTPELZ, E., KORALL, P., SCHNEIDER, H. \& WOLF, P.G. 2006. A classification for extant ferns. Taxon 55(3):705-731.

SMITH, J.F., STEVENS, A.C., TEPE, E.J. \& DAVIDSON, C. 2008. Placing the origin of two species-rich genera in the late cretaceous with later species divergence in the tertiary: a phylogenetic, biogeographic and molecular dating analysis of Piper and Peperomia (Piperaceae). Plant. Syst. Evol. 275(1-2):9-30.

SOUZA, F.S., SALINO, A., VIANA, P.L. \& SALIMENA, F.R.G. 2012. Pteridófitas da Serra Negra, Minas Gerais, Brasil. Acta. Bot. Bras. 26(2):378-390.

STEHMANN, J.R., FORZZA, R.C., SALINO, A., SOBRAL, M., COSTA, D.P. \& KAMINO, L.H.Y. 2009. Plantas da Floresta Atlântica. Instituto de Pesquisas Jardim Botânico do Rio de Janeiro, Rio de Janeiro, 515p.

TRYON, R.M. 1972. Endemic areas and geographic speciation in tropical american ferns. Biotropica 4(3):121-131.

URBAN, I. 1906. Vitae Itineraque Collectorum Botanicorum, Notae Collaboratorum Biographicae, Florae Brasiliensis Ratio Edendi Chronologica, Systema, Index Familiarum. In Flora brasiliensis (C.F.P.D. Martius, A.G. Eichler \& I. Urban, eds). Typographia Regia, Monachii, v. $1,487 \mathrm{p}$.

VELOSO, H.P., RANGEL-FILHO, A.L.R. \& LIMA, J.C. 1991. Classificação da vegetação brasileira, adaptada a um sistema universal. Instituto Brasileiro de Geografia e Estatística, Rio de Janeiro, 124 p.

VERSIEUX, L.M. \& WENDT, T. 2007. Bromeliaceae diversity and conservation in Minas Gerais state, Brazil. Biodvers. Conserv. 16: 2989-3009.

VIANA, P.L. \& LOMBARDI, J.A. 2007. Florística e caracterização dos campos rupestres sobre canga na serra da Calçada, Minas Gerais, Brasil. Rodriguésia 58(1):159-177.

WEBSTER, G.L. 1995. The panorama of neotropical cloud forest. In Biodiversity and Conservation of Neotropical Montane Forests (S.P. Churchill, H. Balslev, E. Forero \& J.L. Luteyn, eds.) The New York Botanical Garden, New York, p.53-77.

YUNCKER, T.G. 1972. The Piperaceae of Brazil I - Piper: Group I, II, III, IV. Hoehnea 2:19-366.

YUNCKER, T.G. 1973. The Piperaceae of Brazil II - Piper: Grupo V, Ottonia, Pothomorphe, Sarcorhachis. Hoehnea 3: 29-284.

YUNCKER, T.G. 1974. The Piperaceae of Brazil III - Peperomia, Taxa of uncertain status. Hoehnea 4:71-413. 